\title{
Honeywell
}

\section{KCP Activities Supporting the W76LEP Stress Cushions and LK3626 RTV Replacement Material Development}

- Data Retrieval for 115 Sets of W76-0 Stress Cushions

- Stress Cushion Shrinkage Study "Cinderella Molds"

- Establishing Material Standards Requirements for the RTV Material Reactants

Federal Manufacturing \& Technologies

J. W. Schneider

KCP-613-8649

Distributed October 2009

Topical Report on 044288

Approved for public release; distribution is unlimited.

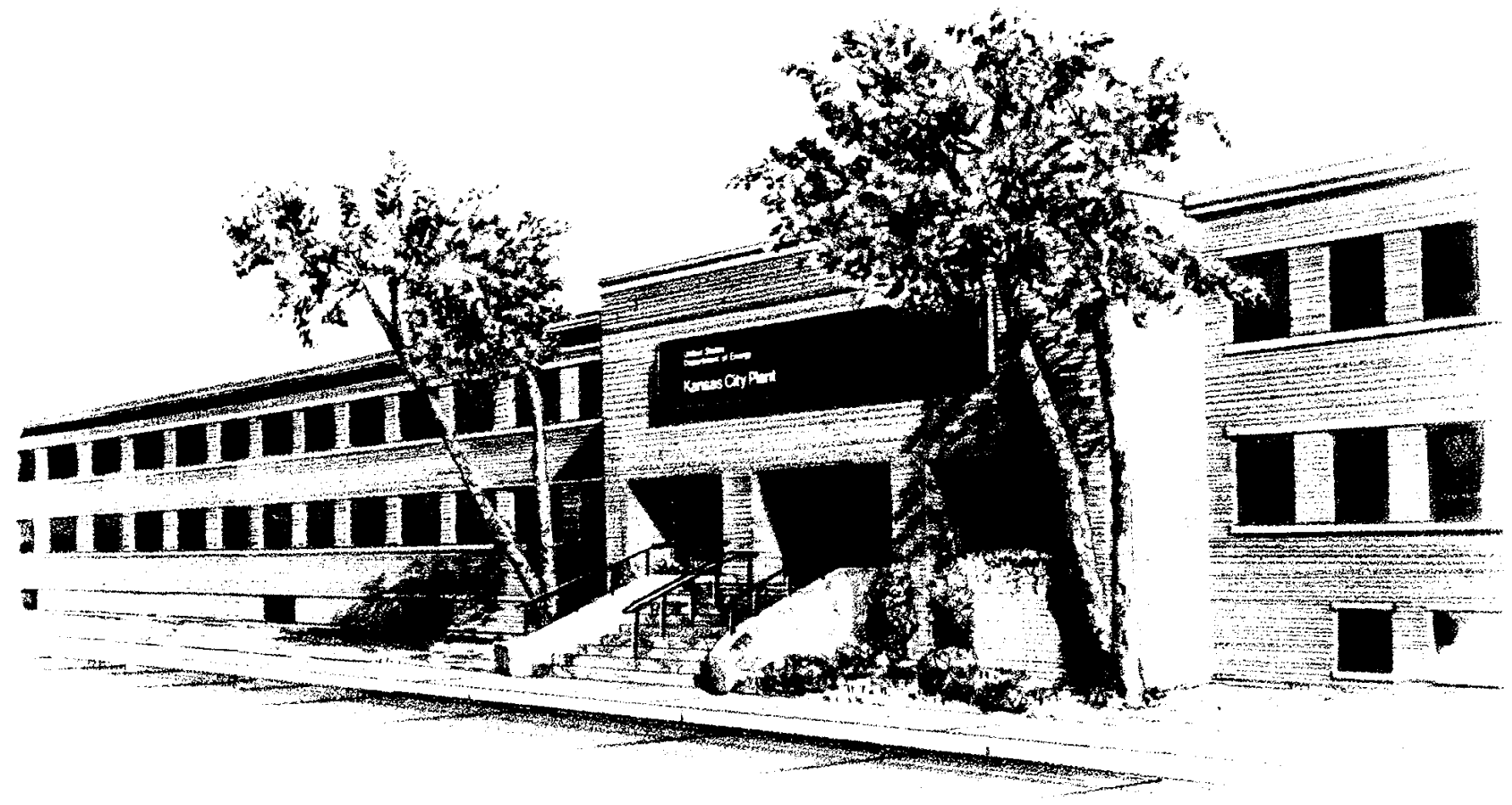




\section{DISCLAIMER}

This report was prepared as an account of work sponsored by an agency of the United States Government. Neither the United States Government nor any agency thereof, nor any of their employees, makes any warranty, express or implied, or assumes any legal liability or responsibility for the accuracy, completeness, or usefulness of any information, apparatus, product, or process disclosed, or represents that its use would not infringe privately owned rights. Reference herein to any specific commercial product, process or service by trade names, trademark, manufacturer, or otherwise, does not necessarily constitute or imply its endorsement, recommendation or favoring by the United States Government or any agency thereof. The views and opinions of authors expressed herein do not necessarily state or reflect those of the United States Government or any agency thereof.

All data prepared, analyzed and presented has been developed in a specific context of work and was prepared for internal evaluation and use pursuant to that work authorized under the reference contract. Reference herein to any specific commercial product, process or service by trade name, trademark, manufacturer, or otherwise, does not necessarily constitute or imply its endorsement, recommendation or favoring by the United States Government, any agency thereof or Honeywell Federal Manufacturing \& Technologies, LLC.

Printed in the United States of America.

This report has been reproduced from the best available copy.

Available to DOE and DOE contractors from the Office of Scientific and Technical Information, P.O. Box 62, Oak Ridge, Tennessee 37831; prices available from (865) 576-8401, FTS 626-8401.

Available to the public from the National Technical Information Service, U.S. Department of Commerce, 5285 Port Royal, Rd., Springfield, Virginia 22161, (703) 487-4650.

A prime contractor with the United States Department of Energy under Contract Number DE-AC04-O1AL66850
Honeywell Federal Manufacturing \& Technologies P.O. Box 419159 Kansas City, Missouri, 64141-6159 


\section{Honeywell}

KCP-613-8649

Distribution Category UC-42

Approved for public release; distribution is unlimited.

J. W. Schneider

Department 832

KCP-613-8649

Distributed October 2009

Topical Report on 044288

Project Team

V. Chhahira

D. E. Bowen

E. A. Eastwood

J. W. Schneider

J. Zeman 


\section{Contents}

Section

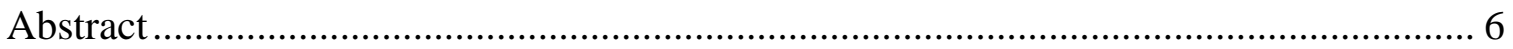

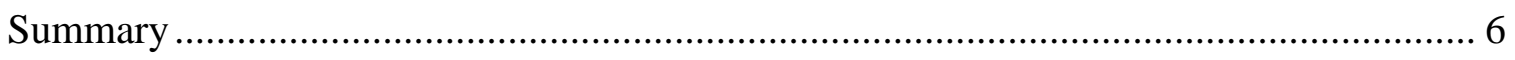

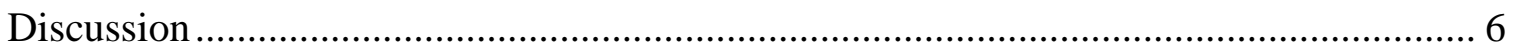

Data Retrieval for 115 Sets of Program Stress Cushions ........................................ 6

Stress Cushion Shrinkage Study "Cinderella Mold” .............................................. 6

Establishing Material Standards Requirements for the RTV Material Reactants ........ 7

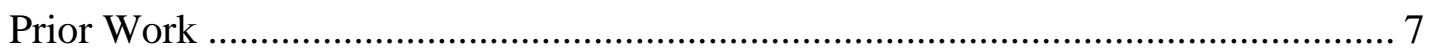

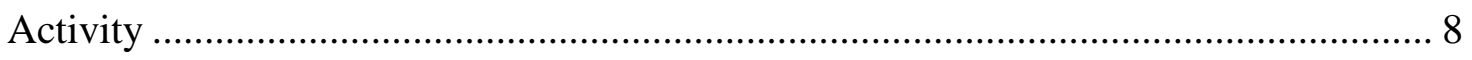

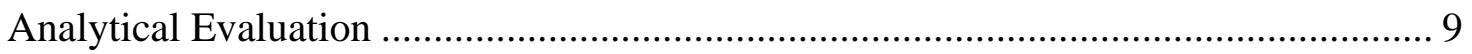

Polydimethylsiloxanediol - 4003028 through 4003030 ...................................... 9

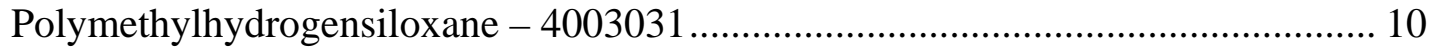

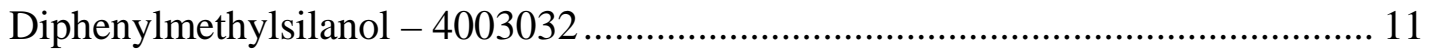

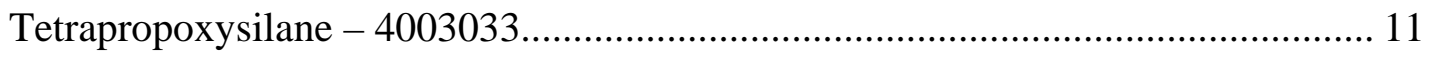

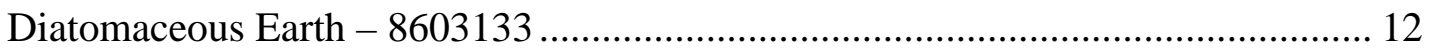

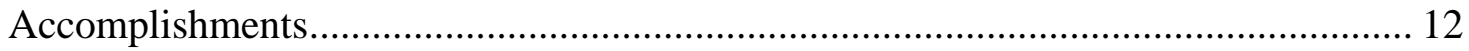

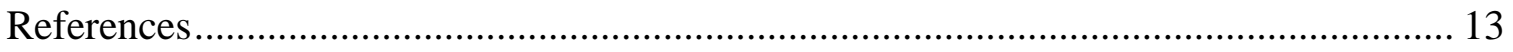

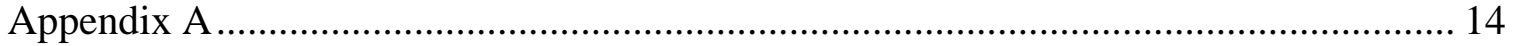

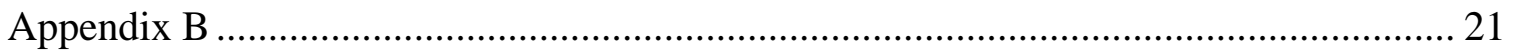

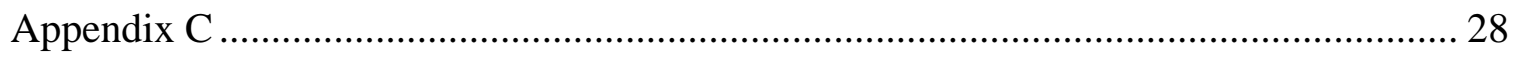

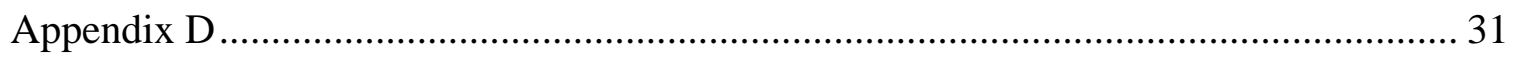

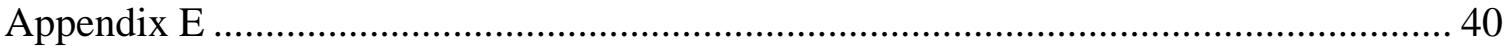

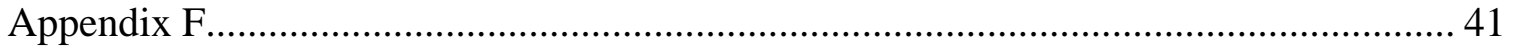

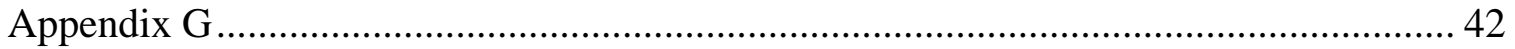

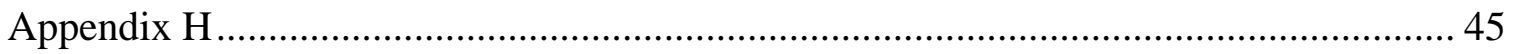

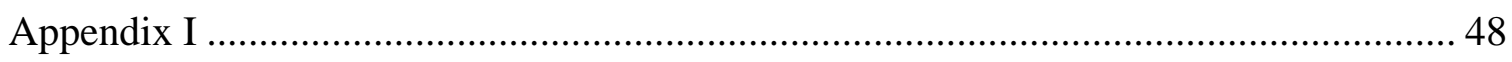

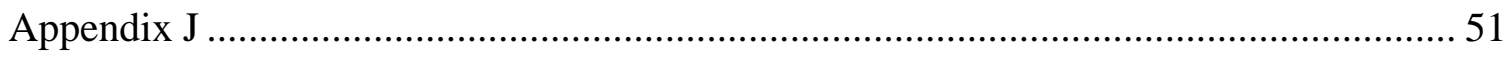




\begin{abstract}
The S-5370 RTV blown foam previously produced by Dow Corning is no longer commercially available. The S-5370 material has been used on all of Los Alamos National Laboratory (LANL) programs to manufacture Stress Cushions up through the W88. The Kansas City Plant (KCP) did not have a sufficient supply of S-5370 material to cover the schedule requirements for the Program. This report provides information on the numerous activities conducted at KCP involving the development of the Program Stress Cushion and replacement RTV material.
\end{abstract}

\title{
Summary
}

LANL requested numerous activities from KCP during the development of the Program Stress Cushion and replacement RTV blown foam material. This report describes several of the requested activities. The first activity requested by LANL was the retrieval of the original load deflection acceptance data for 115 sets of the Number 1 and Number 2 Program Stress Cushions. At a later date, additional material information was requested for these sets, including the material type, lot number of the RTV resin and catalyst, date molded (month/year), resin and catalyst weights, and final trimmed part weight for each part number and serial number. Also described in this report are activities involved in determining the shrinkage of the stress cushion based on the LK3626 RTV foam. Parts were fitted to various cavity contours to determine the best fit and the resulting total shrink factor for molding the Stress Cushion. In addition, this report contains information concerning the establishment of the material standards for the starting reactants for the RTV blown foam. Included is the data from gel permeation chromography (GPC) analytical tests that were used to establish some of the material standards requirements.

\section{Discussion}

\section{Data Retrieval for 115 Sets of Program Stress Cushions}

On June 3, 2003, KCP received a fax from LANL listing 115 serial numbers for the Number 1 and Number 2 Program Stress Cushions. The request was to provide LANL with the WR load deflection acceptance data, and was the first activity involving KCP for the Program. Examples of the data provided for a Number 1 and Number 2 are shown in Appendix A and B, respectively. The analysis of this data was completed by LANL and was referred to as the 115 Serial Number Data Set. Requests for information regarding these 115 sets of serial numbers continued to grow, and included resin type, resin lot number, catalyst lot number, date code, resin weight, catalyst weight, and trimmed part weight. The complete listing is shown in Appendix C. KCP was required to provide data only and was not involved in any analysis of the load deflection or material information.

\section{Stress Cushion Shrinkage Study "Cinderella Mold"}

In the October, 2004, time frame, LANL indicated to KCP that the Program stress cushions being provided to them for evaluation purposes did not fit the inner contour of the next assembly. The parts were loose or small and tended to pull away from the next 
assembly waist area. A review of the KCP tool drawing indicated a $2 \%$ shrinkage factor, or 0.020 inch / inch. This is the same shrinkage factor that has been used on all KCP RTV blown foam contour tooling starting with the Program in approximately 1976.

With the extreme flexibility of these stress cushions, it is impossible to obtain any direct measurement from a part. The part is flexible enough to stretch over a slightly larger contour than what it was designed for. So, for determination of fit, the part would need to be evaluated in an inner contour situation. KCP devised a plan to evaluate the stress cushion to the next assembly inner contour. The inner contour would be machined into a clear material, so the stress cushion fit could be evaluated from all angles. A total of four acrylic molds, deemed the Cinderella molds, were machined at various contours. The four inner contours were based on variations from the nominal contour of the next assembly. The first mold was machined to the exact nominal contour and would be considered $100 \%$ or no shrinkage. The second mold was machined at $99 \%$ of the contour or $1 \%$ shrinkage. The third mold was cut to $98.5 \%$ of the contour or $1.5 \%$ shrinkage. The fourth mold was cut to $98 \%$ of the contour or $2 \%$ shrinkage.

When these Cinderella molds were completed, LANL representatives evaluated the fit of approximately 80 stress cushions produced under various conditions. The stress cushions were molded between May 21 and December 9, 2004, at pour weights between 37.0 and 44.5 grams. The catalyst levels were varied from $5 \%$ to $7 \%$ and all of these conditions were based on seven different lots of LK3626 resin formulated at KCP. The review sheets, provided to LANL personnel on December 16, 2004, containing this part information are shown in Appendix D. An analysis of the data was performed by LANL to determine the appropriate material shrinkage. The results of the capability analysis for the Cinderella test are shown in Appendix E. Statistically, 3.5\% shrinkage was optimum as determined by LANL. This is based on $2 \%$ from the perform mold and $1.5 \%$ from the Cinderella mold. KCP presented a slide on April 13, 2005, summarizing the test conditions and results, as shown in Appendix F. The WR perform mold, initial molding of the stress cushion, and the WR compression set molds are all designed with the 3.5\% shrink factor applied.

\section{Establishing Material Standards Requirements for the RTV Material Reactants}

\section{Prior Work}

In the late 1970s, Dr. G. Keith Baker, a polymer chemist with Bendix, initiated work to de-engineer the S-5370 formulation. Dr. Baker's formulation consisted of the following materials: low molecular weight silanol, high molecular weight silanol, polymethylhydrosiloxane, tetrapropoxysilane, diphenylmethylsilanol, and diatomaceous earth. $^{1}$

Cindy W. Sandoval (LANL) led several efforts to optimize this formulation. The resulting replacement material for the S-5370 was deemed LK3626. The resulting LK3626 formulation is: low molecular weight silanol, low / high molecular weight 
silanol, high molecular weight silanol, polymethylhydrosiloxane, tetrapropoxysilane, diphenylmethylsilanol, and diatomaceous earth. ${ }^{2,3}$

\section{Activity}

The LK3626 is based on the following materials: three different molecular weight polydimethylsiloxanediols designated as low molecular weight siloxane (LMWS), low high molecular weight siloxane (LHMWS), high molecular weight siloxane (HMWS), polymethylhydrosiloxane (PMHS), tetrapropoxysilane (TPS), diphenylmethylsilanol (DPMS), and diatomaceous earth (DE). These materials are all available commercially from a minimum of two sources, except the DPMS.

During development of the LK3626, numerous lots of starting materials were obtained by KCP for evaluation and the establishment of material standards acceptance criteria. The nonproduction part numbers and the WR material standards for each of the constituents of the LK3626 are shown in Table 1. 
Table 1. Starting Materials for the Formulation of the LK3626

\begin{tabular}{|c|c|c|c|c|c|}
\hline Material & Designation & Vendor & Vendor ID & $\begin{array}{c}\text { Material } \\
\text { Standard }\end{array}$ & $\begin{array}{c}\text { Non } \\
\text { Production \# }\end{array}$ \\
\hline $\begin{array}{c}\text { Polydimethylsiloxanediol } \\
\text { (low molecular weight) }\end{array}$ & LMWS & NuSil & PLY 7601 & 4003028 & 57010379 \\
\hline $\begin{array}{c}\text { Polydimethylsiloxanediol } \\
\text { (low molecular weight) }\end{array}$ & LMWS & UCT & PS 340 & 4003028 & 57010386 \\
\hline $\begin{array}{c}\text { Polydimethylsiloxanediol } \\
\text { (low high molecular weight) }\end{array}$ & LHMWS & NuSil & PLY 7608 & 4003029 & 57010380 \\
\hline $\begin{array}{c}\text { Polydimethylsiloxanediol } \\
\text { (low high molecular weight) }\end{array}$ & LHMWS & UCT & PS 342.5 & 4003029 & 57010387 \\
\hline $\begin{array}{c}\text { Polydimethylsiloxanediol } \\
\text { (high molecular weight) }\end{array}$ & HMWS & NuSil & PLY 7609 & 4003030 & 57010381 \\
\hline $\begin{array}{c}\text { Polydimethylsiloxanediol } \\
\text { (high molecular weight) }\end{array}$ & HMWS & UCT & PS 343.8 & 4003030 & 57010388 \\
\hline $\begin{array}{c}\text { Polymethylhydrogensiloxane } \\
\text { (trimethyl endblocked) }\end{array}$ & PMHS & NuSil & XL-132 & 4003031 & 57010382 \\
\hline $\begin{array}{c}\text { Polymethylhydrogensiloxane } \\
\text { (trimethyl endblocked) }\end{array}$ & PMHS & UCT & PS 120 & 4003031 & 57010389 \\
\hline $\begin{array}{c}\text { Polymethylhydrogensiloxane } \\
\text { (trimethyl endblocked) }\end{array}$ & PMHS & Dow Corning & DC 1107 & 4003031 & 57010391 \\
\hline \begin{tabular}{c} 
Diphenylmethylsilanol \\
\hline Tetrapropoxysilane
\end{tabular} & DPMS & NuSil & PLY 7602 & 4003032 & 57010383 \\
\hline Tetrapropoxysilane & TPS & UCT & T2090 & 4003033 & 57010390 \\
\hline \begin{tabular}{c} 
Diatomaceous Earth \\
\hline
\end{tabular} & DE & Celite & Celite 350 & 8603133 & 57010385 \\
\hline
\end{tabular}

NuSil - NuSil Silicone Technology

UCT - United Chemical Technologies

Celite - Celite Corporation

\section{Analytical Evaluation}

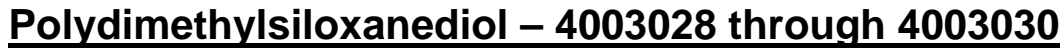

GPC was utilized to determine the molecular weight for the following polydimethylsiloxanediol materials: LMWS, LHMWS, and HMWS. The GPC results for all three materials are shown in Appendixes G - I, respectively. It should be noted that for the 4003028, LMWS, only the NuSil material was available for evaluation. Samples from NuSil and United Chemical Technologies were available for evaluation for the LHMWS 4003029 and the HMWS 4003030. 
Jim Wyckoff, KCP Statistician, evaluated the GPC results and established weight average molecular weights and tolerances based on a 95\% probability. These values, shown in Table 3, were reviewed and slightly rounded.

Table 2. 95\% Probability Molecular Weights - Finalized for 4003028 through 4003030

\begin{tabular}{|c|c|c|}
\hline Material - Part Number & $\begin{array}{c}\text { Weight Average } \\
\text { Molecular Weight }\end{array}$ & Drawing Requirement \\
\hline LMWS - 4003028-a & $2,352 \pm 579$ & $2,350 \pm 580$ \\
\hline LHMWS - 4003029-a & $29,377 \pm 3696$ & $29,400 \pm 3700$ \\
\hline HMWS - 4003030-a & $54,291 \pm 6990$ & $54,300 \pm 7000$ \\
\hline
\end{tabular}

Additional testing of these three materials includes visual, viscosity, and moisture determination. The visual requirement is clear and free of particulates. The requirements for viscosity and moisture are to determine and report only.

A sample from $40 \%$ of the containers, rounded up to the next whole number, shall be taken for molecular weight and visual requirements. A sample from $25 \%$ of the containers, rounded up to the next whole number, shall be taken for the viscosity and moisture determination.

The shelf life of this material is six months from the date of shipment. Any material exceeding this age shall be reinspected to the requirements of molecular weight, visual, viscosity, and moisture. If the material passes, the shelf life may be extended six months. By retesting, the shelf life may be extended for six month intervals indefinitely. Material failing the requirements of molecular weight, visual, viscosity, and moisture shall be scrapped.

\section{Polymethylhydrogensiloxane - 4003031}

Gel permeation chromography (GPC) was utilized to determine the molecular weight for this polymethylhydrogensiloxane material, PMHS. The GPC results for the PMHS material from the three vendors NuSil, United Chemical Technologies, and Dow Corning are shown in Appendix J.

Jim Wyckoff, KCP Statistician, evaluated the GPC results and established weight average molecular weights and tolerances based on a 95\% probability. These values, shown in Table 3, were reviewed and slightly rounded.

Table 3. 95\% Probability Molecular Weights - Finalized for 4003031

\begin{tabular}{|c|c|c|}
\hline Material - Part Number & $\begin{array}{c}\text { Weight Average } \\
\text { Molecular Weight }\end{array}$ & Drawing Requirement \\
\hline PMHS - 4003031-a & $12,152.5 \pm 5899.5$ & $12,150 \pm 5900$ \\
\hline
\end{tabular}


Additional testing of these three materials includes visual, viscosity, and moisture determination. The visual requirement is clear and free of particulates. The requirements for viscosity and moisture are to determine and report only.

A sample from $40 \%$ of the containers, rounded up to the next whole number, shall be taken for molecular weight and visual requirements. A sample from $25 \%$ of the containers, rounded up to the next whole number, shall be taken for the viscosity and moisture determination.

The shelf life of this material is six months from the date of shipment. Any material exceeding this age shall be reinspected to the requirements of molecular weight, visual, viscosity, and moisture. If the material passes, the shelf life may be extended six months. By retesting, the shelf life may be extended for six month intervals indefinitely. Material failing the requirements of molecular weight, visual, viscosity, and moisture shall be scrapped.

\section{Diphenylmethylsilanol - 4003032}

Gas Chromography / Mass Spectrum (GCMS) was utilized to analyzed the diphenylmethylsilanol material, DPMS, for purity. The GCMS results for this material indicate that the DPMS generally consists of a combination of the following materials: diphenylmethylsilanol, methoxydiphenylmethylsilane, and ethoxydiphenymethylsilane. Based on this information, the material standard states that the GCMS results for the DPMS shall consist of any combination of the above mentioned compounds. The visual requirement is clear and free of particulates. It should be noted that for the 4003032, DPMS, only one source, NuSil Technology, was available for this material.

A sample from each of the containers shall be taken for purity and visual requirements.

The shelf life of this material is six months from the date of shipment. Any material exceeding this age shall be reinspected to the requirements of GCMS and visual. If the material passes, the shelf life may be extended six months. By retesting, the shelf life may be extended for six month intervals indefinitely. Material failing the requirements of GCMS and visual shall be scrapped.

\section{Tetrapropoxysilane -4003033}

GCMS was utilized to analyze the tetrapropoxysilane material, TPS, for purity. The GCMS results for this material from both NuSil Technology and United Chemical Technologies indicates that it generally is well above 95\% purity. So, 95\% was set as the minimum acceptable value for this material in the material standard. The visual requirement is clear and free of particulates.

A sample from $50 \%$ of the containers, rounded up to the next whole number, shall be taken for purity and visual requirements. 
The shelf life of this material is six months from date of shipment. Any material exceeding this age shall be reinspected to the requirements of GCMS / purity and visual. If the material passes, the shelf life may be extended six months. By retesting, the shelf life may be extended for six months intervals indefinitely. Material failing the requirements of GCMS / purity and visual shall be scrapped.

\section{Diatomaceous Earth - 8603133}

The Celite 350 is a "Buy By Label” material with unlimited shelf life and is available from the Celite Corporation.

\section{Accomplishments}

The details of activities involved in establishing some of the material standards requirements (limits) are now documented. A review of the testing and percentage of containers tested for each material is shown in Table 4.

Table 4. Test Parameters and Percentage of Containers Tested by Material

\begin{tabular}{|l|c|c|c|c|c|c|c|}
\hline & LMWS & LHMWS & HMWS & PMHS & DPMS & TPS & Celite 350 \\
\hline Molecular Wt., Mw & $40 \%$ & $40 \%$ & $40 \%$ & $40 \%$ & N/A & N/A & N/A \\
\hline Viscosity & $25 \%$ & $25 \%$ & $25 \%$ & $25 \%$ & N/A & N/A & N/A \\
\hline Moisture & $25 \%$ & $25 \%$ & $25 \%$ & $25 \%$ & N/A & N/A & N/A \\
\hline Purity & N/A & N/A & N/A & N/A & $100 \%$ & $50 \%$ & N/A \\
\hline Visual & $40 \%$ & $40 \%$ & $40 \%$ & $40 \%$ & $100 \%$ & $50 \%$ & N/A $^{*}$ \\
\hline
\end{tabular}

* Celite 350 is a "Buy By Label” material.

As of August 25, 2009, all starting materials for any RTV formulation have been obtained only from NuSil Technology. 


\section{References}

${ }^{1}$ G. Keith Baker, Silicone Technology Development, Quarterly Report for FY-80-1, October/December, 1979.

${ }^{2}$ Cynthia W. Sandoval, Formulation of a Hydrogen Blown Silicone Foam, Advanced Materials Experiment, MS 790-P, 12-13-00.

${ }^{3}$ LK3626 Formulation provided by AER20020300LA on 6/21/02 to KCP. 
Appendix A

Complete Part Load Vs Deflection Report Part Number 1 S/N 1018 


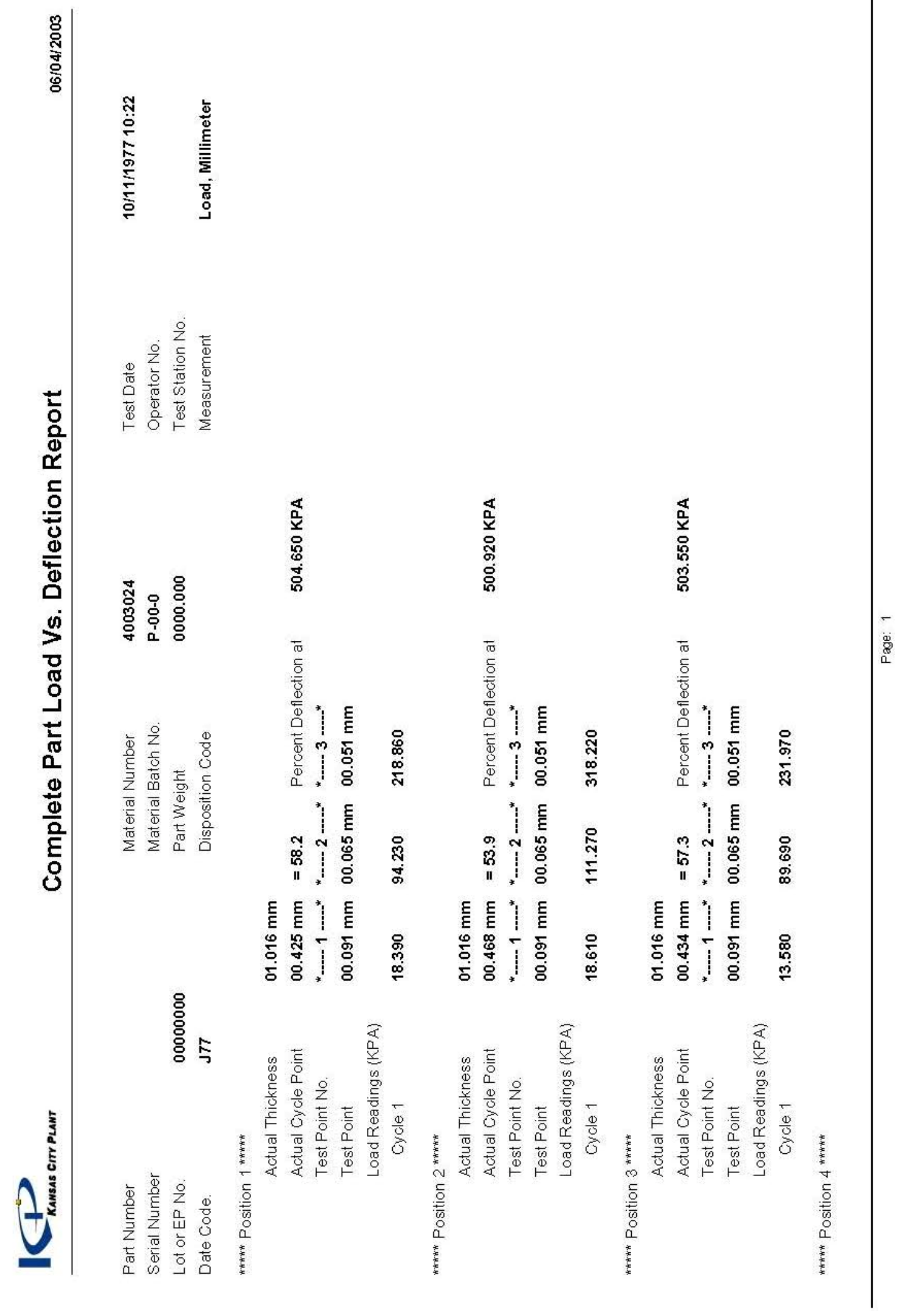




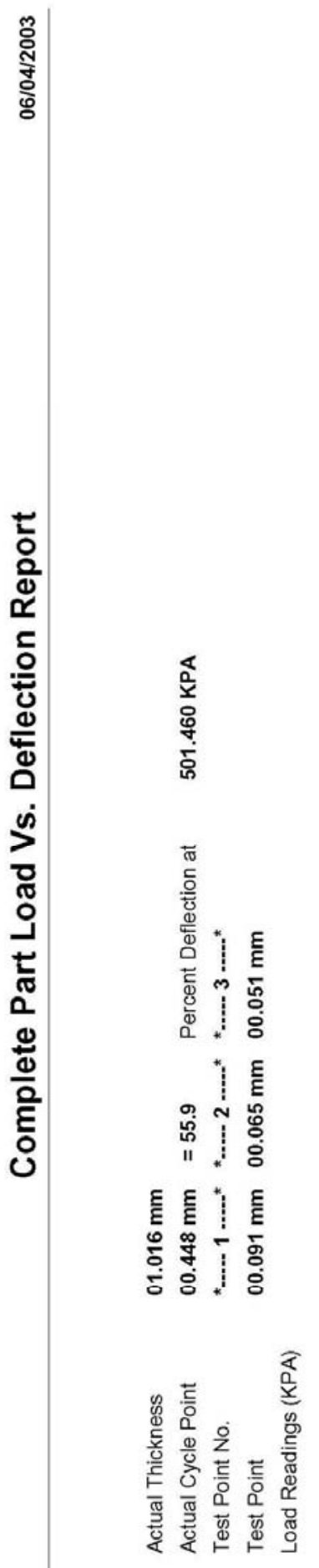




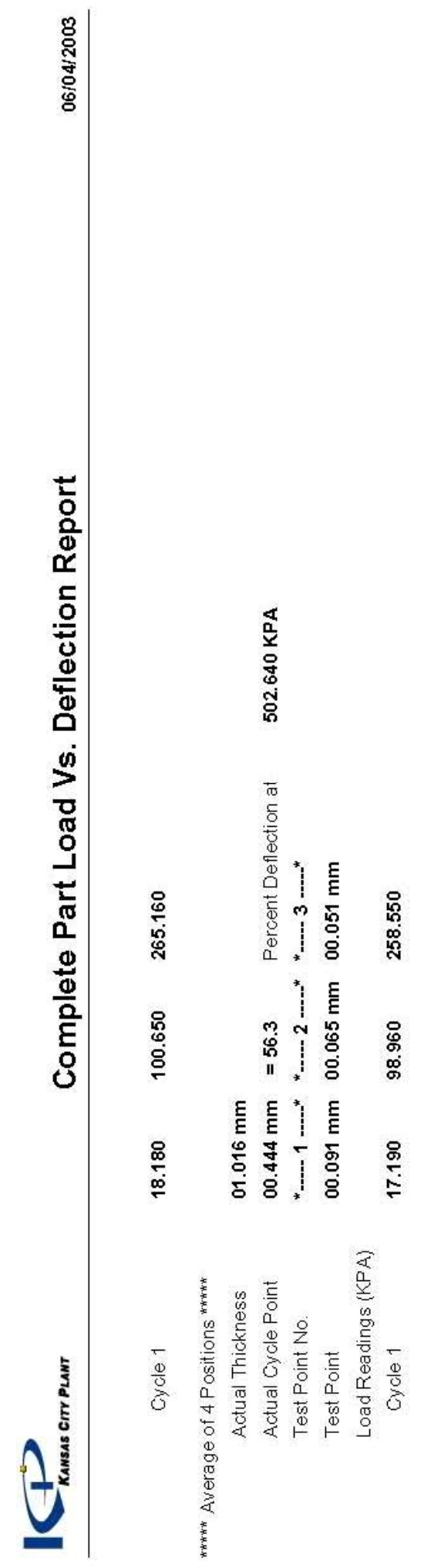




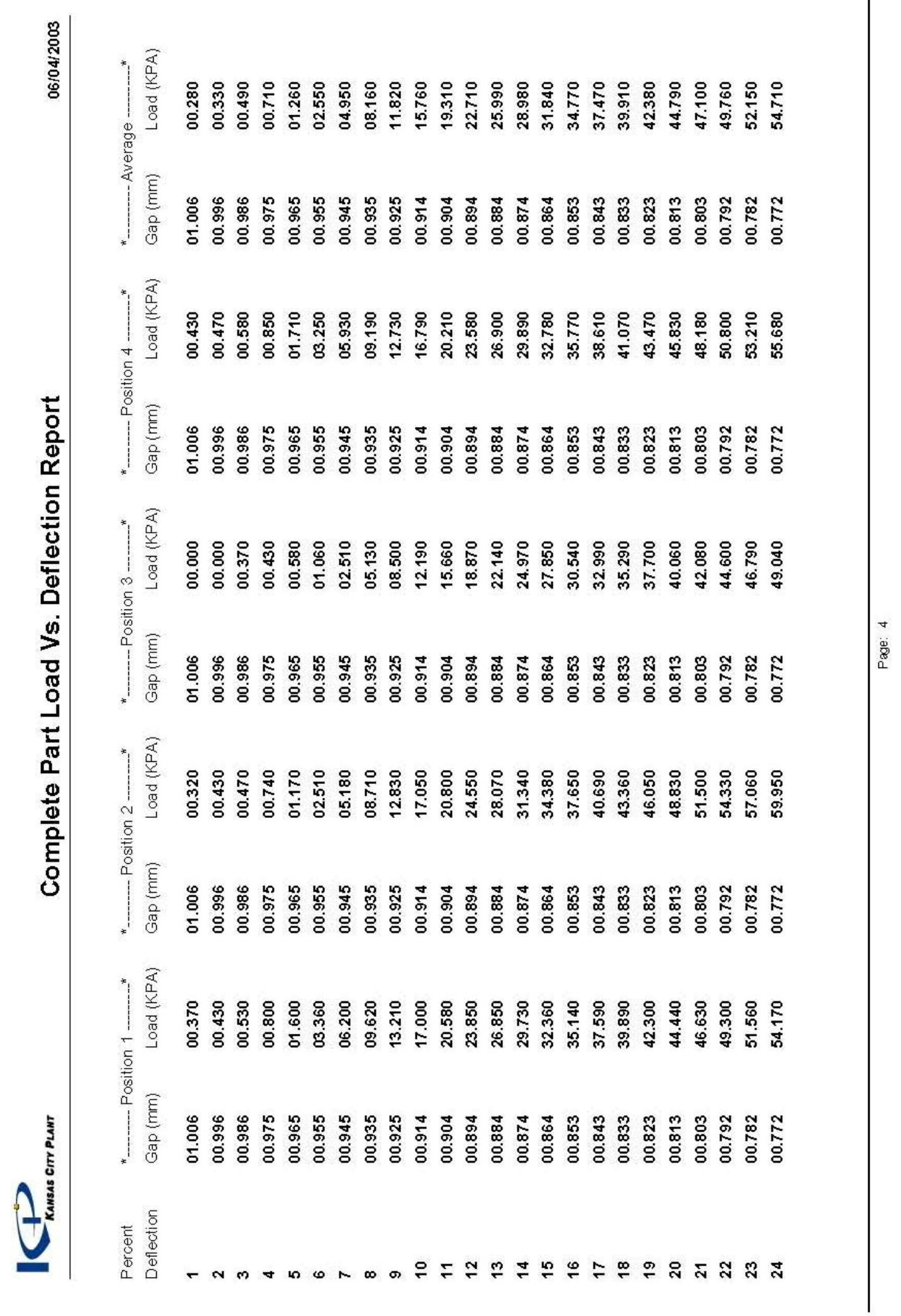




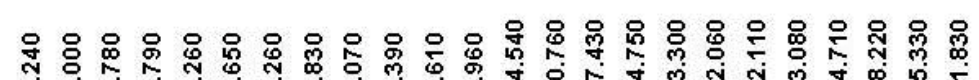

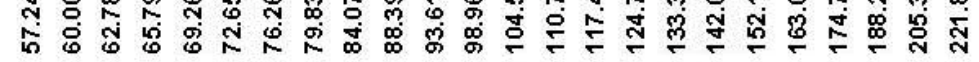

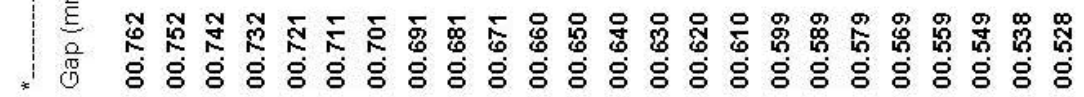

*

官 它

(क)

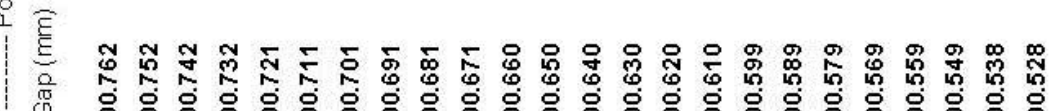

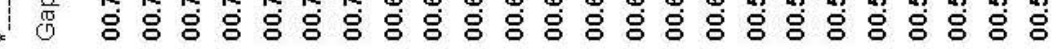

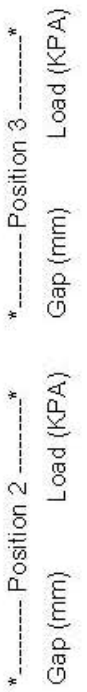

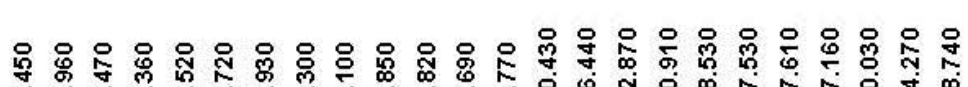

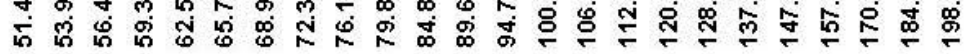

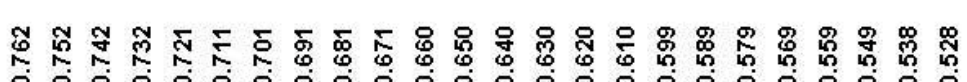

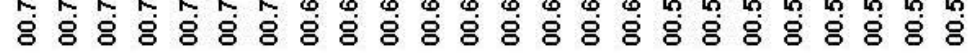

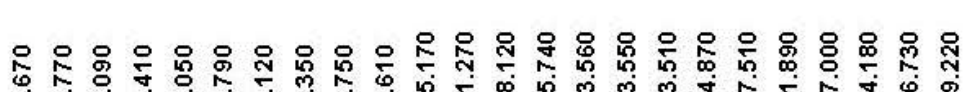

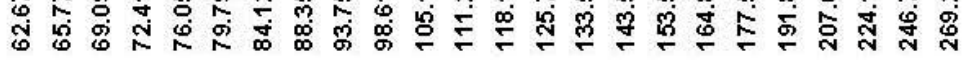

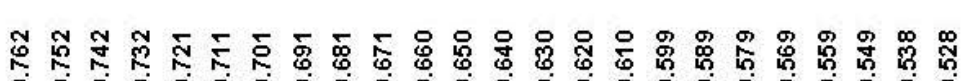

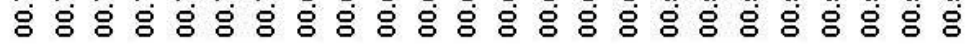

* 疍

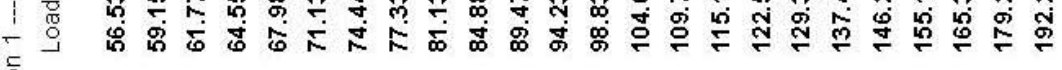
음

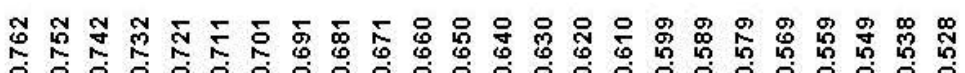

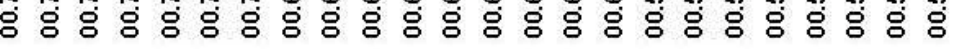

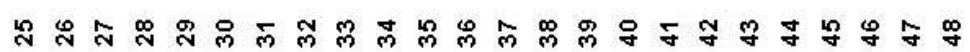




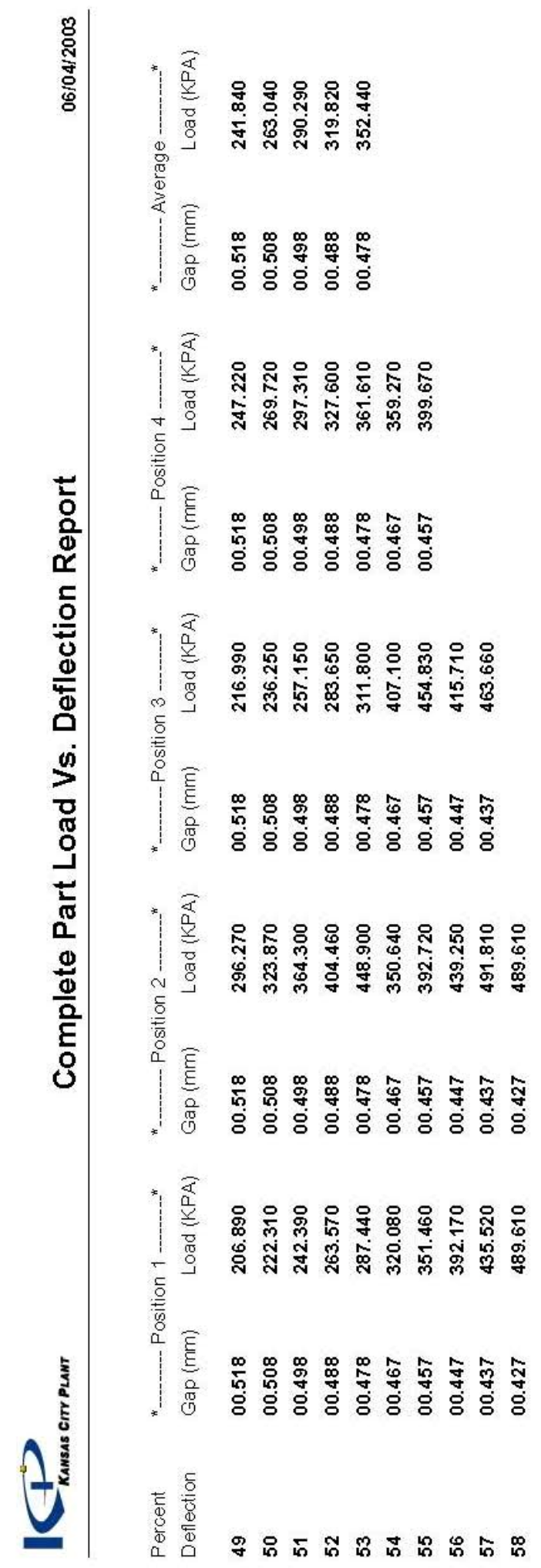




\section{Appendix B \\ Complete Part Load Vs Deflection Report Part Number 2 S/N 1031}




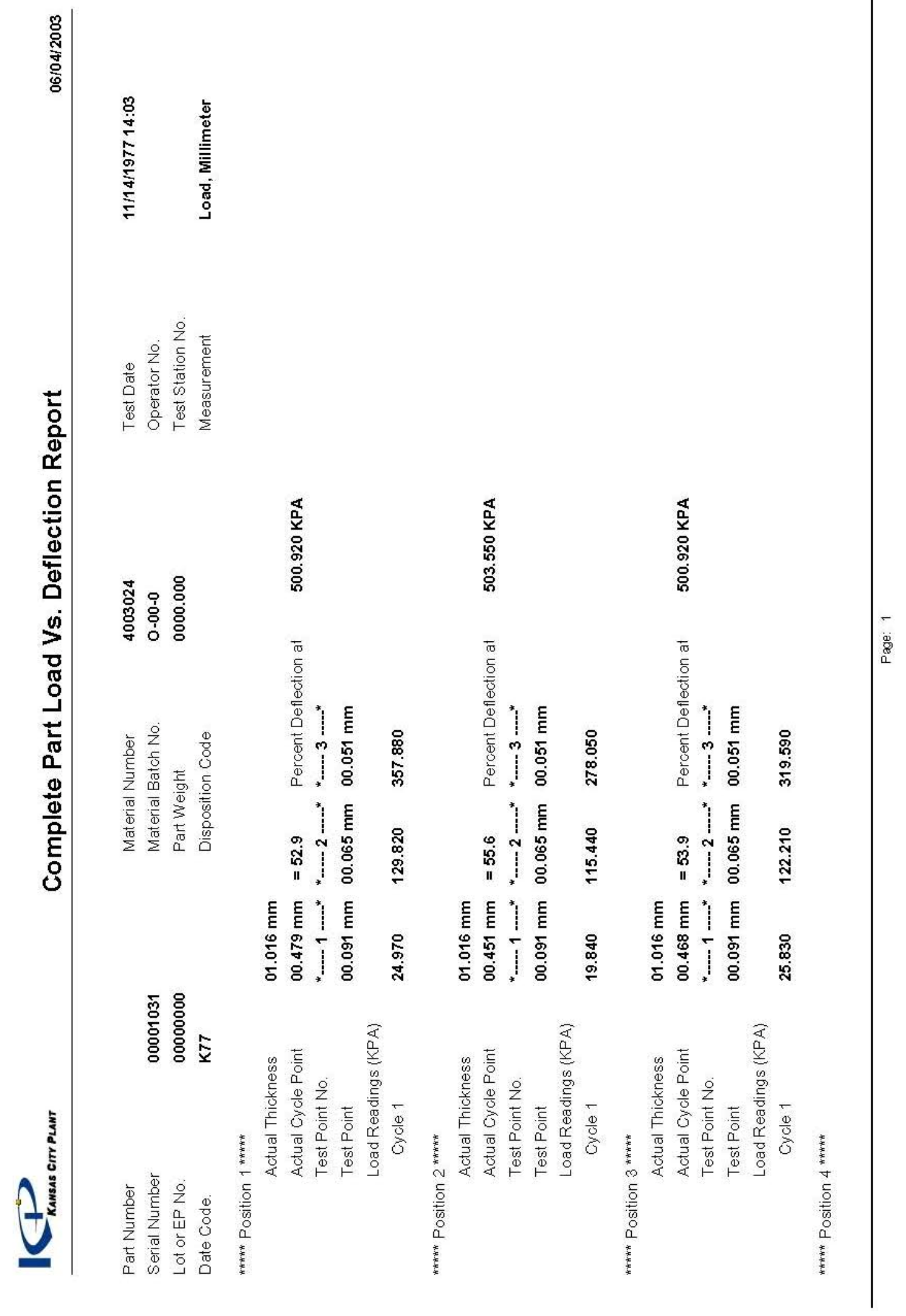




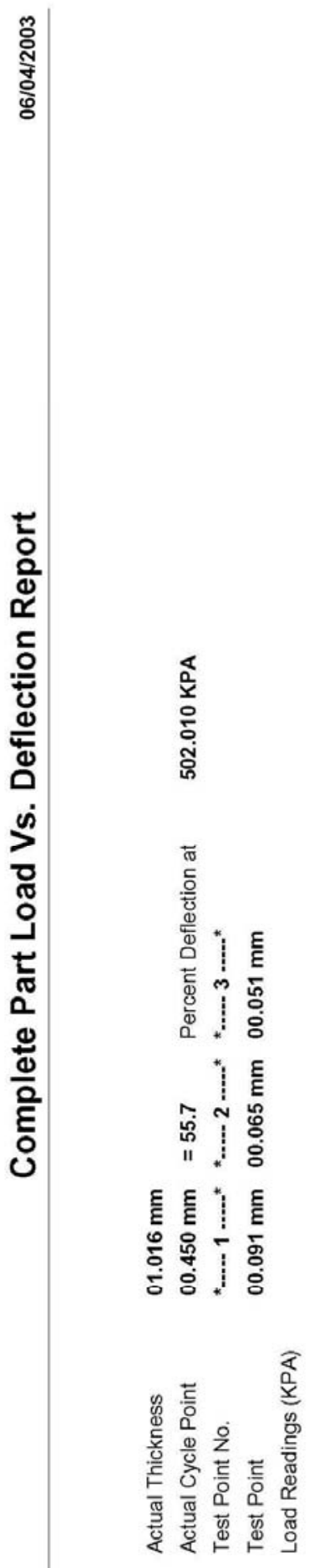




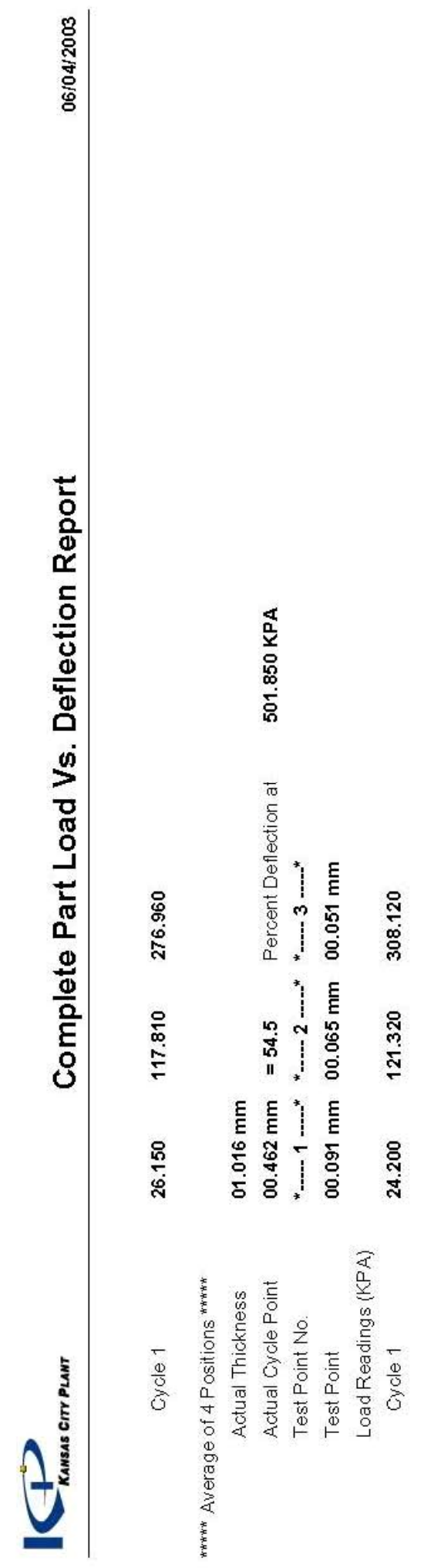




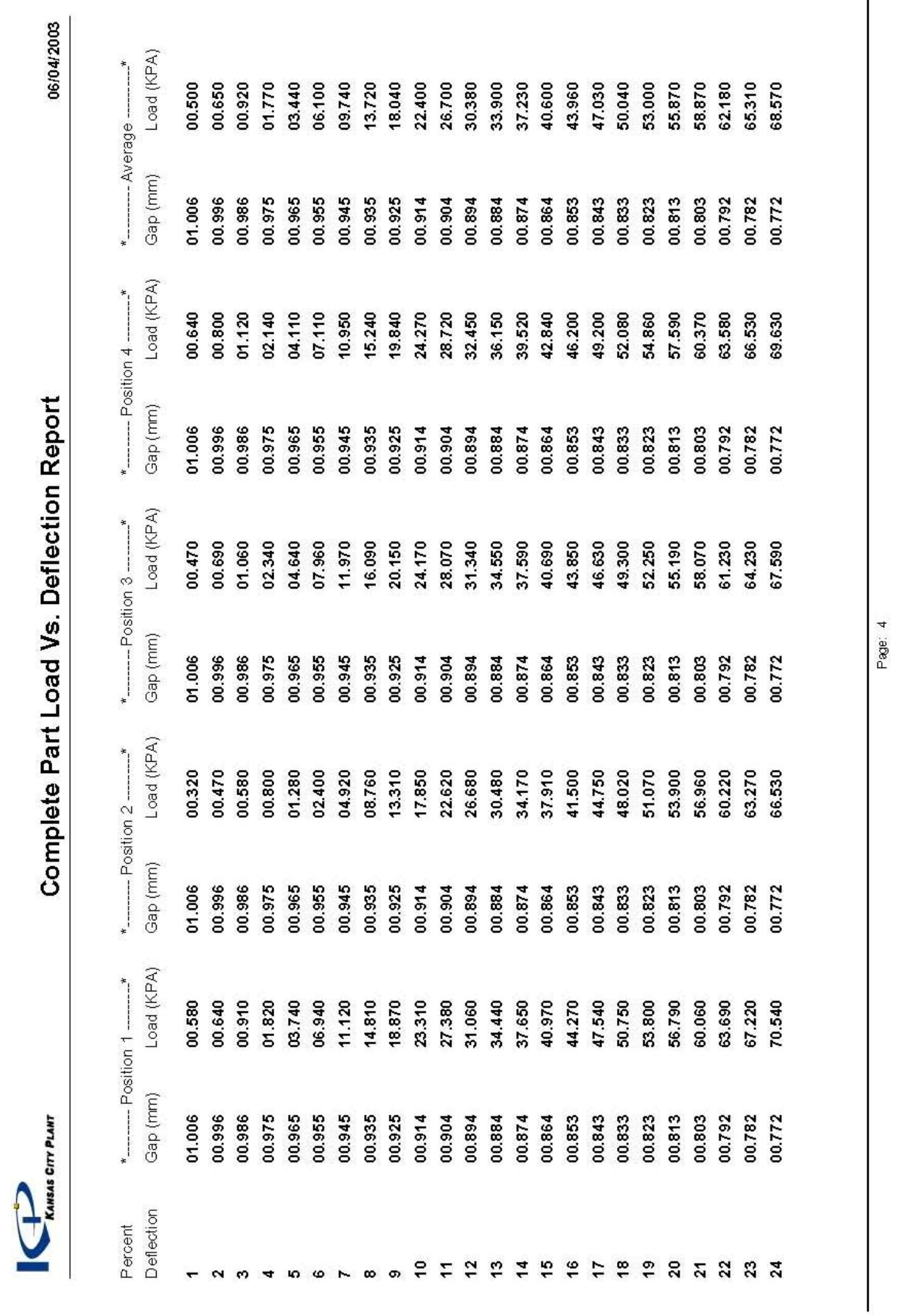




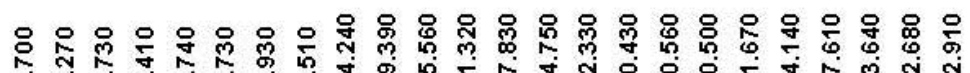

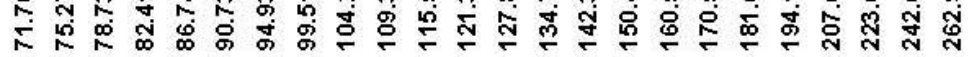

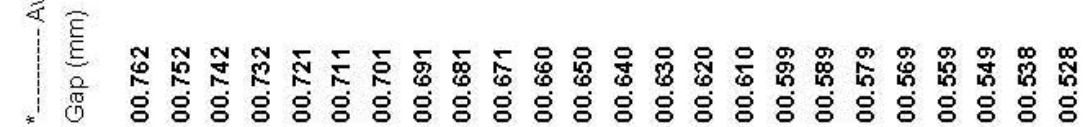

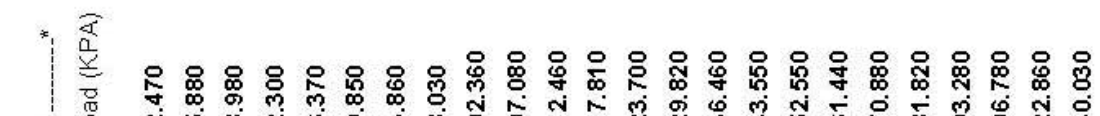

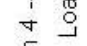

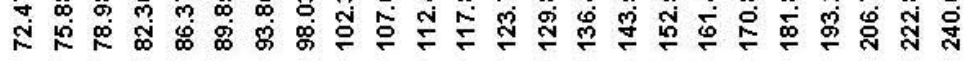

结 \% ठั

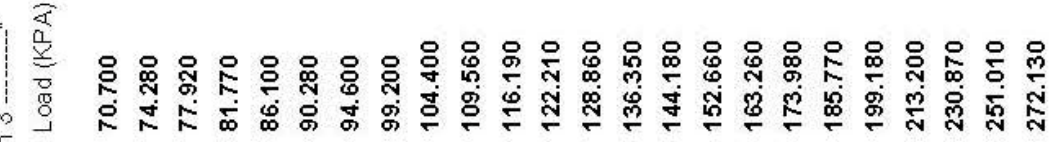

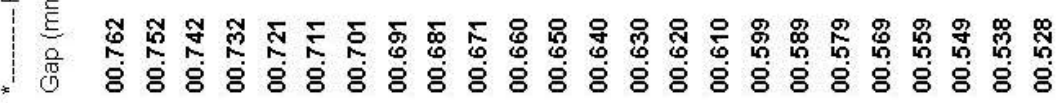

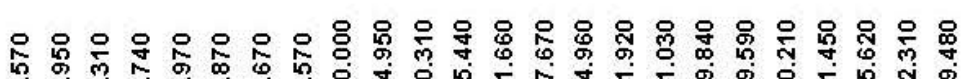

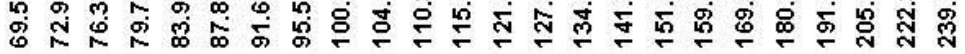

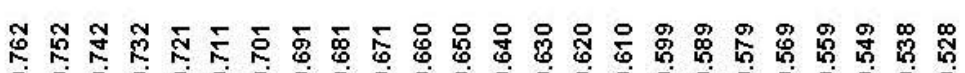

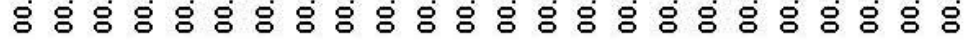

* 重

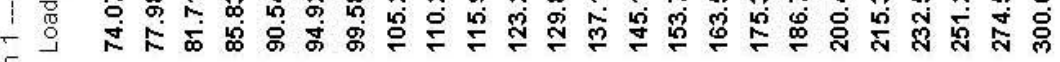
高

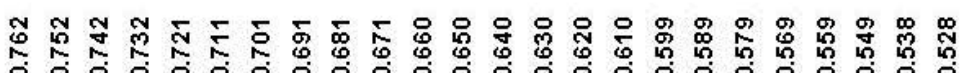

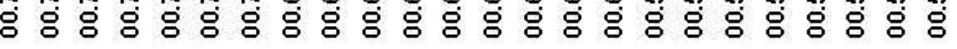

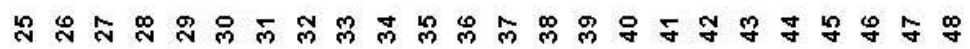




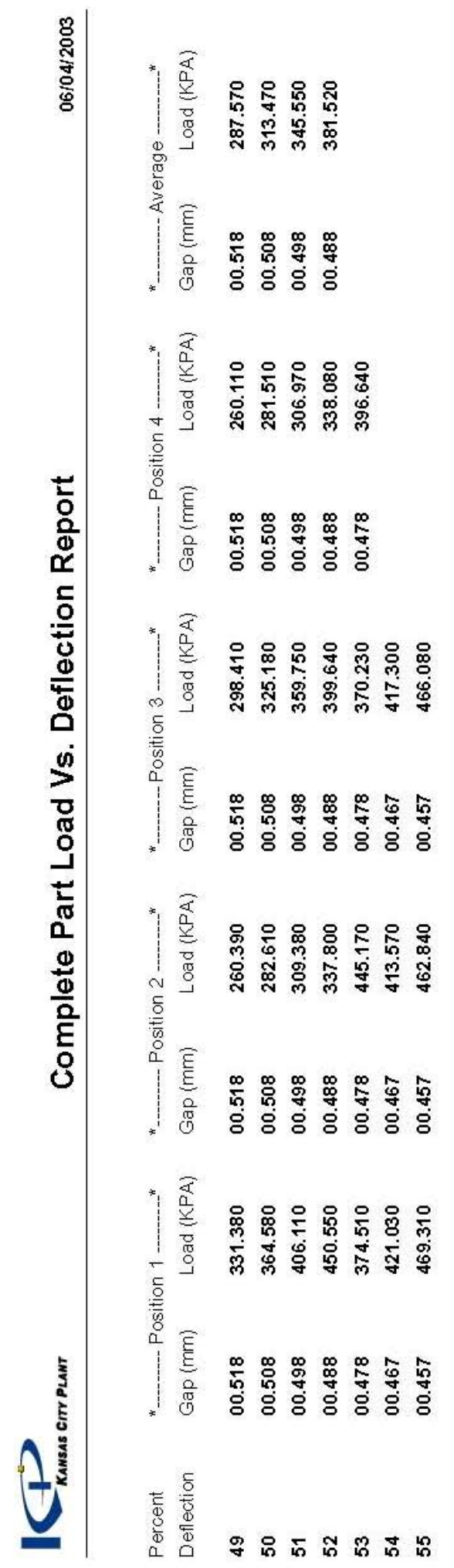




\author{
Appendix C \\ Listing of 115 Data Set with \\ Complete Material Information
}


Listing of 115 Data Set with Complete Material Information

\begin{tabular}{|c|c|c|c|c|c|c|c|c|c|c|c|c|c|c|c|c|}
\hline & & Numb & & & & & & & & Numb & er 2 & & & & & \\
\hline & \begin{tabular}{|c|} 
Materialal \\
Sliasc 38
\end{tabular} & 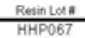 & $\begin{array}{l}\text { Cathens } \\
\text { HHO0773 }\end{array}$ & & & & $\frac{\text { Weight }}{19}$ & $\frac{W \text { Weght (a) }}{303}$ & 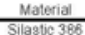 & & & & & & Weigh & Weignt(a) \\
\hline 2 & Slaztc 366 & 7 & HHOOT5 & $c 78$ & $\begin{array}{l}1018 \\
1122\end{array}$ & $\begin{array}{l}38.0 \\
380\end{array}$ & $\begin{array}{l}19 \\
19\end{array}$ & $\begin{array}{l}30.3 \\
301\end{array}$ & $\begin{array}{l}\text { Silasact } 386 \\
\text { Silatic } 386\end{array}$ & 7 & H & $\begin{array}{l}K 77 \\
C 78\end{array}$ & 1133 & $\begin{array}{l}38.0 \\
375\end{array}$ & 19 & (310 \\
\hline & Slazasc: & & Hot & H78 & 1208 & 370 & 18 & 28.9 & & & & & & 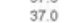 & 18 & 290 \\
\hline${ }^{4}$ & $\mathrm{~s}$ & $880 \pi$ & HHOOT7 & 578 & 1981 & 37.0 & 18 & 29.5 & 96 & & H01875 & H78 & 1336 & 37.0 & & 29.1 \\
\hline & & 68072 & нH0077 & 578 & 1384 & 37.0 & 18 & 29.8 & Silastco 366 & H058072 & HHOOT7 & 578 & 1390 & 37.0 & 18 & 29.8 \\
\hline & & & $\begin{array}{l}\text { HHO0077 } \\
\text { HHOOT7 }\end{array}$ & 178 & $\begin{array}{l}1356 \\
148\end{array}$ & 37.0 & 1.8 & ${ }_{37.9}^{29.6}$ & 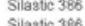 & & & $\begin{array}{l}\text { H778 } \\
78\end{array}$ & 97 & 0 & 1.8 & $n$ \\
\hline 8 & 然 & 8077 & 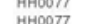 & . & $\begin{array}{l}1458 \\
170\end{array}$ & $\begin{array}{l}350 \\
320\end{array}$ & 18 & $\begin{array}{l}279 \\
258\end{array}$ & 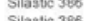 & & HAOOOOT & . 78 . & 17 & $\begin{array}{l}340 \\
330\end{array}$ & 17 & $m$ \\
\hline & & 58072 & HHO & A79 & 1676 & 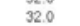 & 1.6 & 260 & & 2 & HнOOT7 & A79 & 11 & 330 & 16 & $\begin{array}{l}208 \\
267\end{array}$ \\
\hline 10 & 30c 386 & 68072 & $\mathrm{HH} 0077$ & A79 & 1762 & 33.0 & 16 & 26.9 & & & HHOOT7 & 97 & & in & 1.6 & 263 \\
\hline & Slassc 386 & HO88074 & нHОOT7 & c79 & 2011 & 330 & 16 & 268 & Sliastco 306 & H058072 & HH0OT7 & A79 & 50 & 32.0 & 16 & 260 \\
\hline & Siastc 386 & H058072 & HH0077 & 879 & 1946 & 33.0 & 1.6 & 26.5 & Silastce 368 & He8074 & нно7т & (1) & & 10 & 16 & 263 \\
\hline 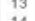 & 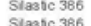 & $\begin{array}{l}\text { Ho88874 } \\
\text { H0s8974 }\end{array}$ & $\begin{array}{l}\text { HH0077 } \\
\text { HHO007 }\end{array}$ & $\begin{array}{l}c 79 \\
c 79\end{array}$ & $\begin{array}{l}2156 \\
2074\end{array}$ & $\begin{array}{l}33.0 \\
330\end{array}$ & ${ }_{16}^{16}$ & 270 & Silasucc 326 & H086074 & Hно077 & & 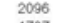 & 33.0 & 1.6 & 268 \\
\hline & $\begin{array}{l}386 \\
0\end{array}$ & $\begin{array}{l}\mathrm{H} 0888074 \\
\mathrm{H}\end{array}$ & HHOOT7 & $\mathrm{C} 79$ & 2116 & $\begin{array}{l}33.0 \\
330\end{array}$ & $\begin{array}{l}16 \\
1.6\end{array}$ & $\begin{array}{l}27.7 \\
27.0\end{array}$ & antce 306 & 068074 & HHOOT7 & c79 & $\begin{array}{l}1777 \\
1907\end{array}$ & $\begin{array}{r}33.0 \\
330\end{array}$ & 18 & 269 \\
\hline 16 & & 88074 & HHOOT7 & (1) & 0 & 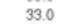 & 16 & ? & 210386 & & 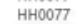 & 急 & 1932 & 33.0 & 16 & $\begin{array}{l}26.9 \\
26.7\end{array}$ \\
\hline & Slazic 386 & 059004 & H118081 & 179 & 2548 & 330 & 1.6 & 26.5 & $13 t c 386$ & HO59004 & 81 & $\mathrm{H} 79$ & 2296 & 33.0 & 1.6 & 269 \\
\hline & Slasac 386 & Ho59004 & H118081 & 179 & 2566 & 33.0 & 1.6 & 28.5 & astc 386 & H069: & H039081 & J79 & 2598 & 33.0 & 16 & 26.7 \\
\hline 19 & sit & 50890044 & $\begin{array}{l}H 180081 \\
H H 0077\end{array}$ & $\begin{array}{l}179 \\
C 79\end{array}$ & $\begin{array}{l}2551 \\
2149\end{array}$ & 33.0 & 16 & $\begin{array}{l}28.1 \\
268\end{array}$ & 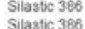 & 74 & HHOOT7 & $\begin{array}{l}\text { C79 } \\
\end{array}$ & ${ }_{2009}^{2100}$ & $\begin{array}{l}33.0 \\
330\end{array}$ & 16 & 26.7 \\
\hline & 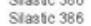 & 059004 & H118081 & H79 & 2400 & 330 & 18 & 27.1 & stic 386 & 74 & 40077 & C79 & 2187 & 330 & 18 & ${ }_{270}^{27.1}$ \\
\hline 22 & sc 386 & HOB9006 & H039081 & & 2726 & 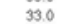 & & 2 & toc 396 & HOQ90006 & H031 & 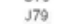 & & 10 & 16 & 270 \\
\hline 23 & tastc 386 & H089006 & H039081 & L79 & 2684 & 33.0 & 16 & 263 & Silastco 326 & HоOध9006 & H039081 1 & $A 80$ & 2638 & 33.0 & 16 & 267 \\
\hline 24 & Slastc 386 & Ho89006 & H039081 & $A B 0$ & 2745 & 33.0 & 1.6 & 26.5 & Silaatic 366 & HO69006 & H03908 1 & ABO & 2712 & 33.0 & 1.6 & 26.4 \\
\hline 2 & 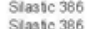 & $\begin{array}{l}H 089006 \\
H 080006\end{array}$ & $\begin{array}{l}\text { H039081 } \\
H 009081\end{array}$ & ${ }^{A B 8}$ & $\begin{array}{l}2765 \\
2861\end{array}$ & $\begin{array}{l}33.0 \\
330\end{array}$ & $\begin{array}{l}16 \\
16\end{array}$ & 27.0 & Silastic 368 & $\begin{array}{r}H 069006 \\
H 089005\end{array}$ & H039081 & ${ }^{A 80}$ & $\begin{array}{l}2679 \\
2644\end{array}$ & 33.0 & 1.6 & 262 \\
\hline & 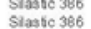 & $\begin{array}{l}\text { Ho899006 } \\
\text { HO89006 }\end{array}$ & 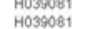 & $\begin{array}{l}{ }_{A B O} \\
A B O\end{array}$ & $\begin{array}{l}2861 \\
2006\end{array}$ & $\begin{array}{l}330 \\
330\end{array}$ & $\begin{array}{l}16 \\
1.6\end{array}$ & 26.1 & $\begin{array}{l}\text { SSlastco } 306 \\
\text { Silatic } 306\end{array}$ & $\begin{array}{l}\begin{array}{r}H 0699006 \\
H 089006\end{array}\end{array}$ & $\begin{array}{l}\text { Ho3039081 } \\
\text { HO393081 }\end{array}$ & ${ }_{A 80}^{A B O}$ & $\begin{array}{l}2664 \\
2632 \\
2032\end{array}$ & $\begin{array}{l}\begin{array}{l}33.0 \\
330\end{array} \\
33\end{array}$ & $\begin{array}{l}1.6 \\
16\end{array}$ & $\begin{array}{l}262 \\
265\end{array}$ \\
\hline & & 109007 & HO19080 & $c_{80}$ & 3045 & & 16 & 26.3 & 306 & & 80 & & 12 & & & \\
\hline 29 & Slazsc 386 & HOB9006 & H039081 & $A B O$ & 2870 & 330 & 16 & 268 & Sllaztic 366 & H01090007 & H0190080 & 880 & 2926 & 33.0 & 16 & 266 \\
\hline 30 & Slazsc 386 & H0109007 & H019080 & 880 & 3027 & 33.0 & 16 & 27.2 & Silastc 306 & H069006 & H039081 & A80 & 2728 & 33.0 & 1.6 & 268 \\
\hline 32 & $\begin{array}{r}\text { Silasact } 386 \\
\text { Silaztc } \\
\end{array}$ & $\begin{array}{l}\text { H01090007 } \\
H 01090007\end{array}$ & $\begin{array}{l}\begin{array}{l}H 019080 \\
H 019080\end{array}\end{array}$ & $\begin{array}{l}{ }_{C 80} 0 \\
C_{00}\end{array}$ & $\begin{array}{l}3362 \\
3048\end{array}$ & $\begin{array}{l}33.0 \\
330\end{array}$ & $\begin{array}{l}16 \\
16\end{array}$ & $\begin{array}{l}267 \\
261\end{array}$ & 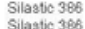 & $\begin{array}{l}\text { H01090007 } \\
\text { HO6 }\end{array}$ & 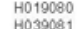 & $\begin{array}{l}8 \mathrm{~B} 80 \\
\mathrm{~A} 80\end{array}$ & $\begin{array}{l}3130 \\
2130\end{array}$ & $\begin{array}{l}33.0 \\
330\end{array}$ & $\begin{array}{l}1.6 \\
16\end{array}$ & $\begin{array}{l}{ }_{266}^{266} \\
270\end{array}$ \\
\hline 33 & 5.5370 & & Ho19080 & 580 & 3510 & 330 & 16 & & $\frac{5.5370}{S .060}$ & & 10081 & & & $\frac{350}{330}$ & & \\
\hline & s-5370 & $\mathrm{Ht}$ & H019 & $c 00$ & 3148 & 330 & 16 & & s-5570 & & & & & & 16 & \\
\hline & \$. 5370 & H0109 & Ho190 & $C 80$ & 3157 & 330 & 16 & 29 & 8.537 & & & & & & 16 & 270 \\
\hline & \$. 5370 & $\mathrm{Ht}$ & Ho19 & ceo & 3259 & 30 & 16 & 26.6 & s.5: & & 30 & B & & 10 & 16 & 263 \\
\hline & $\$ .5370$ & H01090007 & H019080 & $c 80$ & 3170 & 33.0 & 1.6 & 26.7 & $\begin{array}{l}\text { s.5370 } \\
\text { s. }\end{array}$ & & 80 & & & 10 & 1.6 & 27.1 \\
\hline 3 & $\begin{array}{l}s=53770 \\
s-5370\end{array}$ & $\begin{array}{l}H 0109007 \\
\text { H0109008 }\end{array}$ & 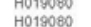 & ${ }_{D \otimes 0}^{C E O}$ & $\begin{array}{l}3325 \\
3448\end{array}$ & $\begin{array}{l}33.0 \\
330\end{array}$ & $\begin{array}{l}16 \\
16\end{array}$ & $\begin{array}{l}26.8 \\
264\end{array}$ & $\begin{array}{l}5.537 \\
5.537\end{array}$ & & 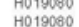 & & & 10 & 16 & $\begin{array}{l}26.7 \\
264\end{array}$ \\
\hline & & H0109000 & H019080 & & & & 1.6 & & \$. 5370 & & & & & & 16 & $\begin{array}{l}26.4 \\
267\end{array}$ \\
\hline & s.5370 & H109008 & H019080 & $D 40$ & 3475 & 33.0 & 1.6 & 26.5 & S.5570 & H01 & H019080 & $C 80$ & ${ }_{35}$ & 10 & 16 & $\begin{array}{l}26.7 \\
26.7\end{array}$ \\
\hline & s.5 & & HO19000 & $c 80$ & 3201 & 33.0 & 16 & 26.3 & S.537, & & HO1 & & & 10 & 6 & 26.7 \\
\hline & S. 5370 & H01090007 & H019080 & $c_{000}$ & $\begin{array}{l}3200 \\
3500\end{array}$ & 330 & 1.6 & 260 & $\begin{array}{l}\text { S. } 5370 \\
55970\end{array}$ & & 30 & & & 33.0 & 16 & 267 \\
\hline 4 & s.53 & $\begin{array}{l}\begin{array}{l}H 109008 \\
H 109008\end{array}\end{array}$ & $\begin{array}{l}R 0190600 \\
H 019000\end{array}$ & $\begin{array}{l}8800 \\
E B 0\end{array}$ & $\begin{array}{l}35009 \\
3813\end{array}$ & 330 & $\begin{array}{l}1.6 \\
18\end{array}$ & $\begin{array}{l}270 \\
272\end{array}$ & S. 55370 & & Hot & & & 10 & 16 & $\begin{array}{l}27.0 \\
27.0\end{array}$ \\
\hline & s.5: & $\mathrm{H}_{1}$ & H019080 & & 36 & & 16 & & $\begin{array}{l}\text { S. } 5370 \\
\text { S }\end{array}$ & 7 & & & & & 16 & 270 \\
\hline & S. 53770 & & H109084 & 881 & ${ }_{37}$ & 32.0 & 16 & 25.9 & s.5. & & & & & & 18 & 26.6 \\
\hline 4 & s.53 & HO2O & H109 & 881 & 3994 & 320 & 16 & 26 & s.5. & H109008 & ${ }_{30}$ & E90 & & 33.0 & 16 & 2 \\
\hline 4 & S. 5370 & H020011 & H1090811 & B81 & 3763 & 32.0 & 1.6 & 26.2 & S.5370 & ${ }^{H 1}$ & H019080 & 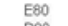 & & 10 & 1.6 & 269 \\
\hline & 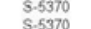 & & $H 109 \%$ & $\begin{array}{l}\text { E80 } \\
{ }_{889}\end{array}$ & $\begin{array}{l}3634 \\
3006\end{array}$ & $\begin{array}{l}330 \\
320\end{array}$ & 16 & & S. 5. & & & & & & 16 & 268 \\
\hline & s.53 & 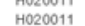 & H109 & $C 81$ & & & 16 & 28 & & & & & & & 16 & $\begin{array}{l}269 \\
265\end{array}$ \\
\hline & s- -5370 & HO200011 & 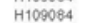 & & & 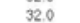 & 16 & 20 & ex & & & & & & 16 & 20.9 \\
\hline 5 & s-5: & & H109084 & B81 & 39 & 20 & 16 & 258 & s: & & & $\mathrm{E}$ & & 330 & 16 & 263 \\
\hline & s. 5370 & $\mathrm{HO}$ & H109084 & G81 & 4 & 32.0 & 1.6 & 25.9 & s.5 & & H110 & C81 & 4246 & 32.0 & 1.6 & 252 \\
\hline 5 & 5.5 & & 600 & $\begin{array}{l}F 81 \\
F_{881}\end{array}$ & & & $\begin{array}{l}16 \\
16\end{array}$ & ${ }_{25}^{26}$ & & & & & & & 16 & \\
\hline & 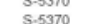 & & H100084 & 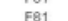 & & & 1.0 & & & & & & & & 16 & \\
\hline 60 & s. 537 & 3020 & 100084 & G81 & ${ }_{4118}$ & 320 & 16 & 262 & S. 5 & - & H100094 & C81 & & 300 & 16 & 26.1 \\
\hline 60 & ${ }_{s .53}$ & $\mathrm{HO}$ & H10: & $\mathrm{G}$ & & & 16 & 26 & & & & & & & 16 & \\
\hline & S.5370 & H020011 & $\mathrm{H} 109084$ & G61 & 4 & 320 & 16 & 26.3 & \$.5370 & & 84 & DET & & 320 & 1.6 & 25.4 \\
\hline 6. & S.5 & & $\begin{array}{l}H 109084 \\
H 100024\end{array}$ & $\mathrm{~GB}_{1}$ & & & 16 & & & & & $=$ & & & 16 & 26.7 \\
\hline & 5.5 & H020011 & 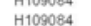 & G81 & & & 16 & 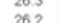 & & & & $\begin{array}{l}E 81 \\
E 81\end{array}$ & & & 10 & 26.6 \\
\hline & S.53 & H021016 & (1) & (6or & & 320 & 0 & 20 & 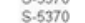 & masor & & DQ1 & & & 10 & 258 \\
\hline $6 t$ & s.s & & 090 & ${ }_{H B} B_{1}$ & & & 16 & 25 & S.537 & & & $\mathrm{FE}$ & & & 16 & tet \\
\hline $67 \mathrm{C}$ & s. & 20011 & $\begin{array}{l}H 1090084 \\
\end{array}$ & $\mathrm{H}$ & & & 1.6 & 26 & & & & $F_{82}$ & & & 16 & 26.7 \\
\hline cis & 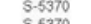 & & H0900 & ${ }^{H e}$ & & & 16 & 26.6 & & & & F & & & 1.6 & 26.7 \\
\hline & & & & & & & 10 & & & & & & & & 10 & $\begin{array}{l}2699 \\
268\end{array}$ \\
\hline & & & & & & & 16 & & & & & & & & & 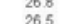 \\
\hline & $\mathrm{se}$ & & $\mathrm{H}$ & KB: & & & 18 & 26 & & & & L8 & & & 16 & 272 \\
\hline & s. 5370 & 11022 & 101093 & $k$ & & 32 & 1.6 & 27.0 & S: 537 & & & L62 & & & 6 & 1 \\
\hline & & & 993 & $\mathrm{~kg}$ & & 32. & 16 & & & & & 4 & & & ${ }^{16}$ & 27.0 \\
\hline & $\begin{array}{l}\text { s. } \\
\text { s.5.5730 }\end{array}$ & & & $A 83$ & & 338 & 16 & 37 & & & & 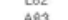 & & & 10 & \\
\hline & & & & $F_{83}$ & & & 16 & & & & & & & & & 2 \\
\hline & s.5: & & & ${ }_{A B 3}$ & 4 & 33. & 1.6 & 26 & S.5370 & & & $A 83$ & 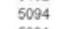 & 33.0 & 16 & 2 \\
\hline 80 & $\begin{array}{l}\text { S.5370 } \\
\text { s.5370 }\end{array}$ & & 2099 & G83 & $\begin{array}{l}5199 \\
5178\end{array}$ & $\begin{array}{l}33.0 \\
330\end{array}$ & 16 & $\begin{array}{l}272 \\
269\end{array}$ & $\begin{array}{l}\$ .5370 \\
\$ .5770\end{array}$ & $\begin{array}{r}\mathrm{HH} 082029 \\
\mathrm{HH}\end{array}$ & $\begin{array}{r}H H 082099 \\
H H\end{array}$ & $\begin{array}{l}F_{883} \\
F 83\end{array}$ & $\begin{array}{l}5221 \\
5284\end{array}$ & $\begin{array}{l}33.0 \\
330\end{array}$ & 1.6 & $\begin{array}{l}27.0 \\
272\end{array}$ \\
\hline & & HHO82029 & 882099 & & & & & & & & HAR0820999 & & & & & \\
\hline
\end{tabular}




\section{Listing of 115 Data Set with Complete Material Information}

\begin{tabular}{|c|c|c|c|c|c|c|c|c|c|c|c|c|c|c|c|c|}
\hline \multirow[b]{2}{*}{$\#$} & \multirow[b]{2}{*}{ Material } & \multicolumn{5}{|c|}{ Number 1} & \multicolumn{2}{|c|}{ Catarne Final Part } & \multirow[b]{2}{*}{ Material } & \multicolumn{5}{|c|}{ Number 2} & \multirow{2}{*}{$\begin{array}{l}\text { Cotaby } \\
\text { Weigte }\end{array}$} & \multirow{2}{*}{$\begin{array}{l}\text { Final pan } \\
\text { Wejuc }\end{array}$} \\
\hline & & Resinlots & Catabnu & Monhnrear & Serialliva & Resin Weight & Weight & Weighta (a) & & Resin Lot: & Catabyat" & MothMrear & Sentu Na & Resin Westit & & \\
\hline 81 & S.5370 & HH082029 & HHOB2099 & $\mathrm{H} 83$ & 5300 & 330 & 1.6 & 27.1 & 5.5370 & HHO82029 & HHO82099 & G83 & 5317 & 330 & 1.6 & 268 \\
\hline 82 & s- 5370 & HHO43032 & HH102101 & 183 & 5363 & 33.0 & 1.6 & 27.3 & S-5370 & HHOB2029 & HHOQ2099 & G83 & 5297 & 33.0 & 16 & 276 \\
\hline 83 & S. 5370 & HHOS2029 & HHOB2099 & 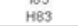 & 5276 & 33.0 & 1.6 & 272 & S. 5370 & HHOB2029 & HHOB2099 & H83 & 5381 & 33.0 & 1.6 & 27.4 \\
\hline 84 & $\frac{3.5370}{S-10}$ & HHOOS3032 & HH102101 & 183 & 5367 & 330 & $\frac{10}{16}$ & 27.1 & $\frac{5.5370}{S-10}$ & 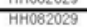 & 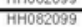 & $\frac{605}{683}$ & 5293 & $\frac{30}{33.0}$ & 16 & 27.3 \\
\hline 85 & S. 5370 & HH043032 & HH102101 & 183 & 5317 & 33.0 & 16 & 26.8 & S. 5370 & HHO82029 & HHO82099 & H83 & 5377 & 33.0 & 16 & 268 \\
\hline 86 & S. 5370 & HH082029 & HHOB2099 & $\mathrm{H} 83$ & 5269 & 33.0 & 1.6 & 270 & S. 5370 & HHO82029 & HHO82099 & $\mathrm{H} 83$ & 5372 & 330 & 16 & 269 \\
\hline 87 & S. 5370 & HHO43032 & HH102101 & 183 & 5428 & 330 & 16 & 27.1 & S. 5370 & HHO82029 & HHO82099 & $\mathrm{H} 83$ & 5401 & 330 & 16 & 273 \\
\hline 88 & S-5370 & HHOB2029 & HHOB2099 & $\mathrm{H} 83$ & 5267 & 33.0 & 16 & 27.2 & S. 5370 & HHO82029 & HHOB2099 & $\mathrm{H} 83$ & 5356 & 33.0 & 16 & 26.7 \\
\hline 89 & S. 5370 & HHO43032 & $\mathrm{HH} 102101$ & 183 & 5316 & 33.0 & 16 & 272 & S. 5370 & HHO43032 & HH102101 & 183 & 5432 & 33.0 & 16 & 262 \\
\hline 90 & s. 5370 & HHO43032 & HH102101 & 183 & 5345 & 330 & 1.6 & 267 & S. 5370 & HHO82029 & HHO82099 & H83 & 5387 & 330 & 16 & 27.1 \\
\hline 91 & 5. 5370 & HHO43032 & HH102101 & $A B 4$ & 5590 & 330 & 16 & 268 & S-5370 & HHOA3032 & HH102101 & 183 & 5494 & 330 & 16 & 272 \\
\hline 92 & 5. 5370 & HHO43032 & HH102101 & $A 84$ & 5435 & 330 & $\begin{array}{l}16 \\
16\end{array}$ & 273 & \$-5370 & HHO4304032 & HH102101 & 183 & 5523 & 330 & 16 & 272 \\
\hline $\begin{array}{l}92 \\
93\end{array}$ & $\begin{array}{l}\text { S.5370 } \\
\text { S-5370 }\end{array}$ & 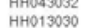 & $\begin{array}{r}H+H 10210109 \\
H H 052097\end{array}$ & $\begin{array}{l}A 34 \\
F 84\end{array}$ & $\begin{array}{l}5435 \\
5665\end{array}$ & $\begin{array}{l}33.0 \\
33.0\end{array}$ & $\begin{array}{l}16 \\
16\end{array}$ & $\begin{array}{l}27.3 \\
274\end{array}$ & $\begin{array}{l}5-53770 \\
\text { S-5370 }\end{array}$ & $\begin{array}{l}H H 104303032 \\
\text { HHO43032 }\end{array}$ & $\begin{array}{l}H+1021010 \\
H H 102101\end{array}$ & A84 & $\begin{array}{l}5523 \\
5670\end{array}$ & $\begin{array}{l}33.0 \\
33.0\end{array}$ & $\begin{array}{l}16 \\
16\end{array}$ & $\begin{array}{l}272 \\
268\end{array}$ \\
\hline 94 & S. 5370 & HHO13030 & HHO52097 & $F_{84}$ & 5680 & 33.0 & 16 & 27.2 & S-5370 & HHO43032 & HH102101 & LB3 & 5558 & 33.0 & 1.6 & 272 \\
\hline 95 & S. 5370 & HHO13030 & HHO52097 & F84 & 5608 & 33.0 & 1.6 & 27.0 & S-5370 & HHO4304032 & HH102101 & A84 & 571 & 33.0 & 1.6 & 26.4 \\
\hline 96 & S-5370 & HHO1 13030 & $\begin{array}{r}H \\
H H O S 2097\end{array}$ & $\mathrm{FB4}$ & $\begin{array}{l}5026 \\
5750\end{array}$ & 33.0 & 1.6 & 27.2 & S-5370 & HHO72028 & $\begin{array}{l}\text { HHOS2097 } \\
\text { P }\end{array}$ & $J 64$ & 5929 & 33.0 & 1.6 & $\begin{array}{l}26.4 \\
26.8\end{array}$ \\
\hline 97 & S. 5370 & HHO6 4040 & HHOS4105 & D85 & 6161 & 330 & 16 & 270 & S. 5370 & HHOT202028 & 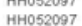 & 184 & 5899 & 330 & $\begin{array}{l}1.6 \\
16\end{array}$ & $\begin{array}{l}26.6 \\
269\end{array}$ \\
\hline 98 & S. 5370 & HHO72028 & HHO52097 & 184 & 5800 & 330 & 1.6 & 264 & S. 5370 & HHOT2028 & HHO52097 & $\mathrm{J84}$ & 5871 & 33.0 & 16 & 270 \\
\hline 99 & S-5370 & HHO23031 & HH102101 & L84 & 5921 & 33.0 & 1.6 & 27.1 & S. 5370 & HHOT2028 & HHOS2097 & $\mathrm{JB4}$ & 5878 & 330 & 16 & 270 \\
\hline 100 & S. 5370 & HН072028 & HHOS2097 & K894 & 5886 & 33.0 & 16 & 270 & S. 5370 & HHOT2028 & HHOS2097 & $\mathrm{HB} 4$ & 5840 & 33.0 & 16 & 27.1 \\
\hline 101 & S. 5370 & HHO23031 & HH102101 & L84 & 5914 & 330 & 1.6 & 26.9 & S. 5370 & HHO23031 & HH1O2101 & $\mathrm{K} 84$ & 5975 & 330 & 16 & 270 \\
\hline 102 & S- 5370 & HHO23031 & HH102101 & $\llcorner 84$ & 5975 & 330 & 1.6 & 27.2 & S. 5370 & HHO23031 & HH102101 & $\mathrm{K} 84$ & 5994 & 33.0 & 16 & 272 \\
\hline 103 & \$-5370 & HHO23031 & HH102101 & 184 & 5981 & 33.0 & 16 & 273 & \$. 5370 & HHO64040 & HHOS4105 & $\mathrm{C} 85$ & 6034 & 330 & 16 & 27.1 \\
\hline 104 & $\begin{array}{l}\$-5370 \\
\text { S. } 5370\end{array}$ & $\begin{array}{l}H H O 23023031 \\
H\end{array}$ & HH102101 & $\begin{array}{r}884 \\
\llcorner 84\end{array}$ & 6026 & $\begin{array}{l}33.0 \\
330\end{array}$ & $\begin{array}{l}16 \\
16\end{array}$ & 270 & $\begin{array}{l}\text { S.53770 } \\
\text { S.5370 }\end{array}$ & HHOO23030 & $\begin{array}{l}\text { HHObU4105 } \\
H H 102101\end{array}$ & K84 & 5996 & 33.0 & $\begin{array}{l}16 \\
16\end{array}$ & 272 \\
\hline $\begin{array}{l}104 \\
105\end{array}$ & $\begin{array}{l}\text { S. } 53700 \\
\text { \$. } 5370\end{array}$ & HHOL64040 & 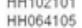 & $C_{C 85}$ & $\begin{array}{l}6026 \\
6081\end{array}$ & $\begin{array}{l}33.0 \\
330\end{array}$ & $\begin{array}{l}16 \\
16\end{array}$ & $\begin{array}{l}270 \\
269\end{array}$ & $\begin{array}{l}\text { S.53370 } \\
\text { S. } 5370\end{array}$ & 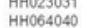 & $\begin{array}{r}H \\
H H 06410201\end{array}$ & $\begin{array}{l}884 \\
C 85\end{array}$ & $\begin{array}{l}59960 \\
6129\end{array}$ & $\begin{array}{l}33.0 \\
33.0\end{array}$ & $\begin{array}{l}16 \\
16\end{array}$ & $\begin{array}{l}272 \\
26.7\end{array}$ \\
\hline 106 & S. 5370 & HHOS 4040 & HHO64 & cos & 6106 & 33 & 16 & 20 & \$. 5370 & HHO64040 & HHO64105 & $\mathrm{C} 85$ & 6079 & 330 & 16 & 268 \\
\hline 107 & $5-5370$ & HH0640.40 & HHO64105 & D85 & 6177 & 33 & 16 & $\begin{array}{l}267 \\
267\end{array}$ & \$. 5370 & HHOOS4040 & HHO64105 & C85 & 6207 & 330 & 16 & 268 \\
\hline 108 & \$- 5370 & HHOS4040 & $\begin{array}{l}\text { HHO64105 } \\
\text { HHOST }\end{array}$ & $c 65$ & 61 & 330 & 1.6 & 260 & S- 5370 & HHO64040 & HHO64105 & C65 & 6069 & 35 & 1.6 & 26.4 \\
\hline 10 & S. 5370 & HHO64040 & & c & & 33.0 & 16 & & & & & $c$ & & & 1.6 & 270 \\
\hline 110 & S-5370 & HHOOA & H & K85 & 6470 & & 1.6 & & & & & & & & 1 & 269 \\
\hline . I & S-5370 & HHO94042 & $\mathrm{HH} 104$ & $\mathrm{~K} 8 \mathrm{~S}$ & 6421 & 33 & 16 & 20 & S-5 & HHOOS4040 & HHOS4105 & K85 & 64 & 330 & 1.6 & 273 \\
\hline 112 & S. 5370 & HHO94042 & HH104106 & $k 85$ & 6527 & 330 & 16 & 270 & S. 53 & HHO904042 & HHO94106 & K85 & 6491 & 330 & 16 & 272 \\
\hline 113 & S. 5370 & HHO94042 & HH104106 & 886 & 6815 & 330 & 16 & 262 & S. 5370 & HHO94042 & HHO94106 & $A 86$ & 6629 & 330 & 16 & 267 \\
\hline 114 & S. 5370 & HHO25045 & HHO35109 & $c 06$ & 6671 & 32.0 & 1.6 & 25.9 & S. 5370 & HHO25045 & HHO35109 & G86 & 6672 & 33.0 & 16 & 266 \\
\hline 115 & S. 5370 & HH094042 & HHO94108 & 886 & 6594 & 330 & 18 & 270 & s. 5370 & HH025045 & HHO35109 & $C 86$ & 6693 & 330 & 16 & 269 \\
\hline
\end{tabular}


Appendix D

Individual Part Information for the Cinderella Mold Evaluation 


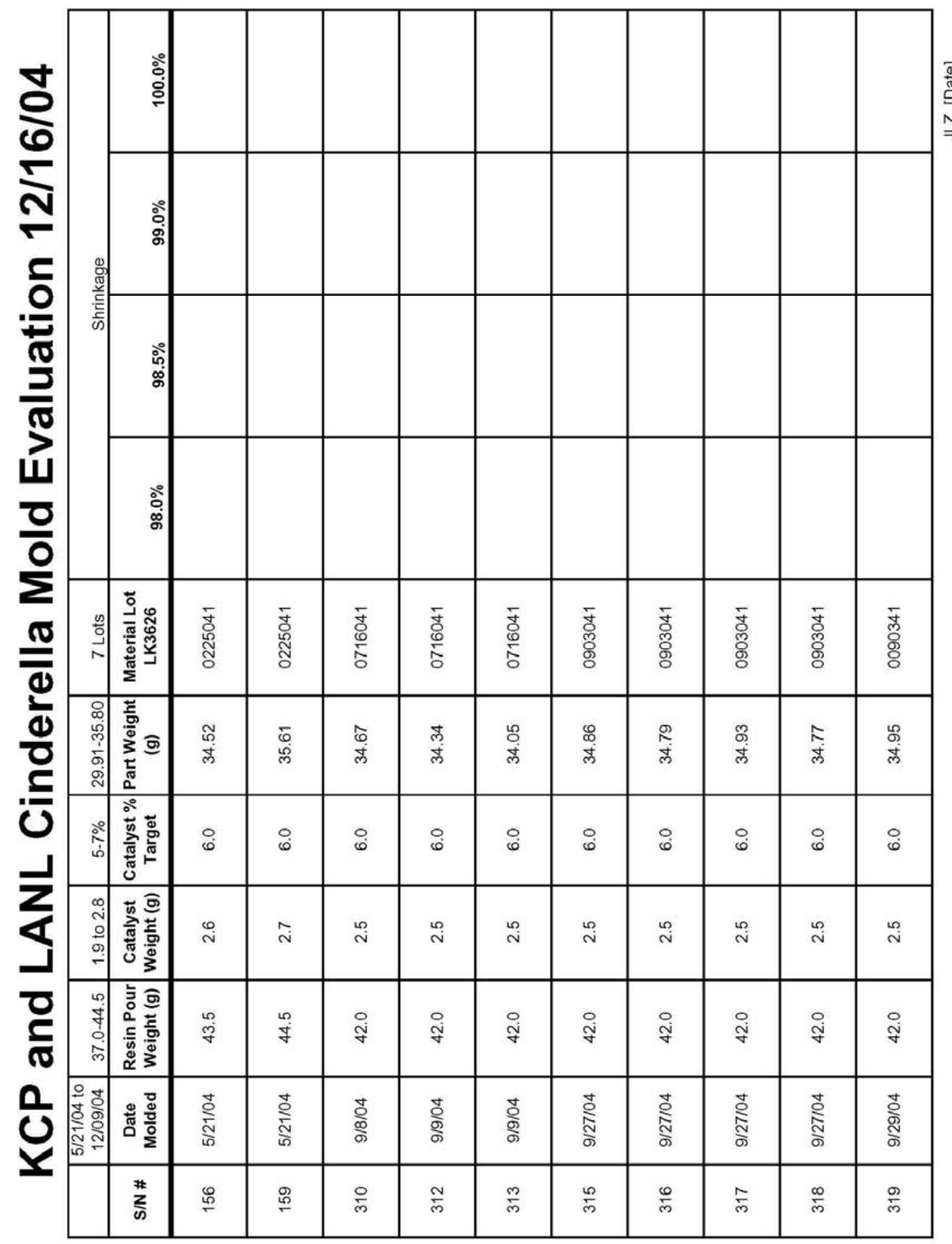




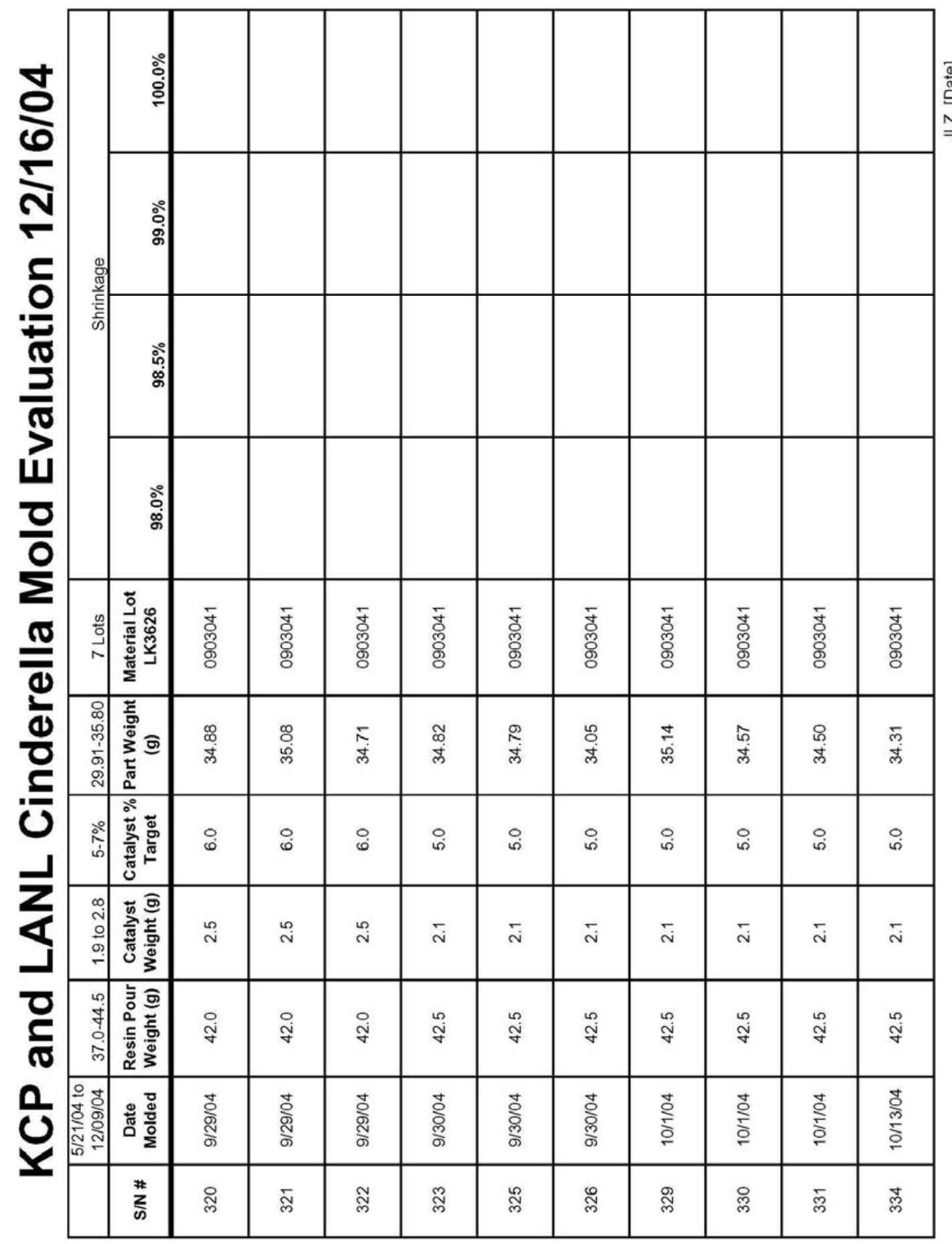




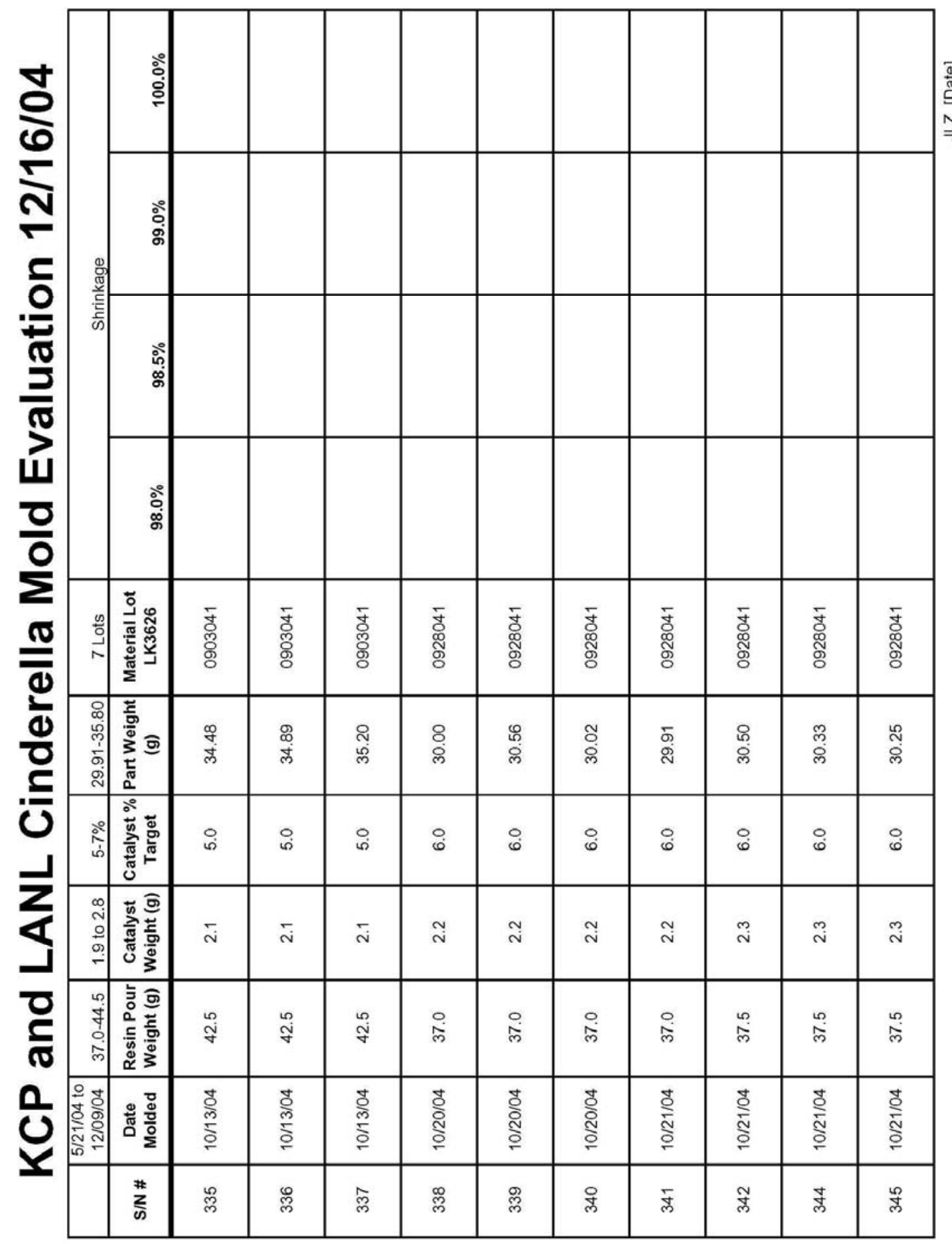




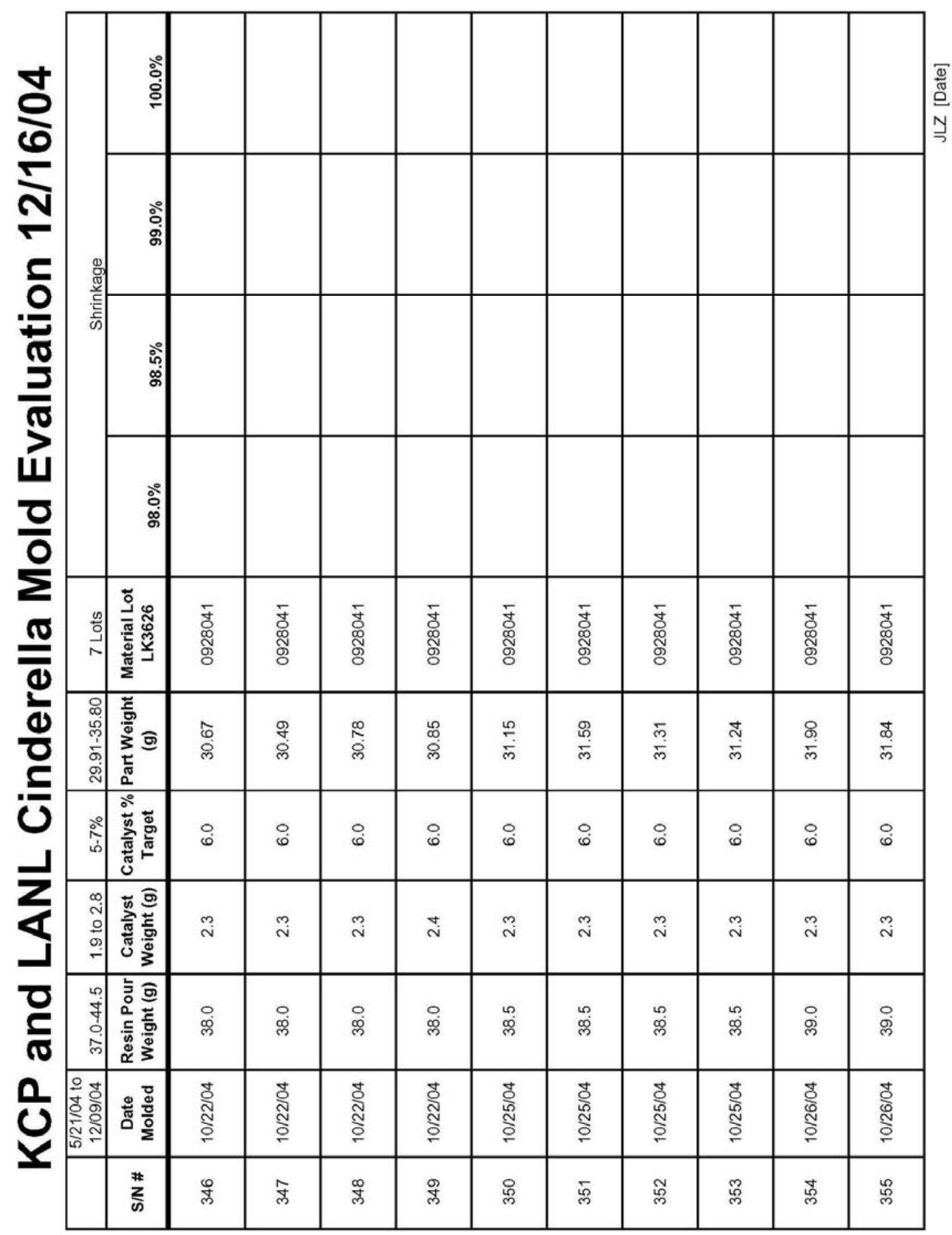




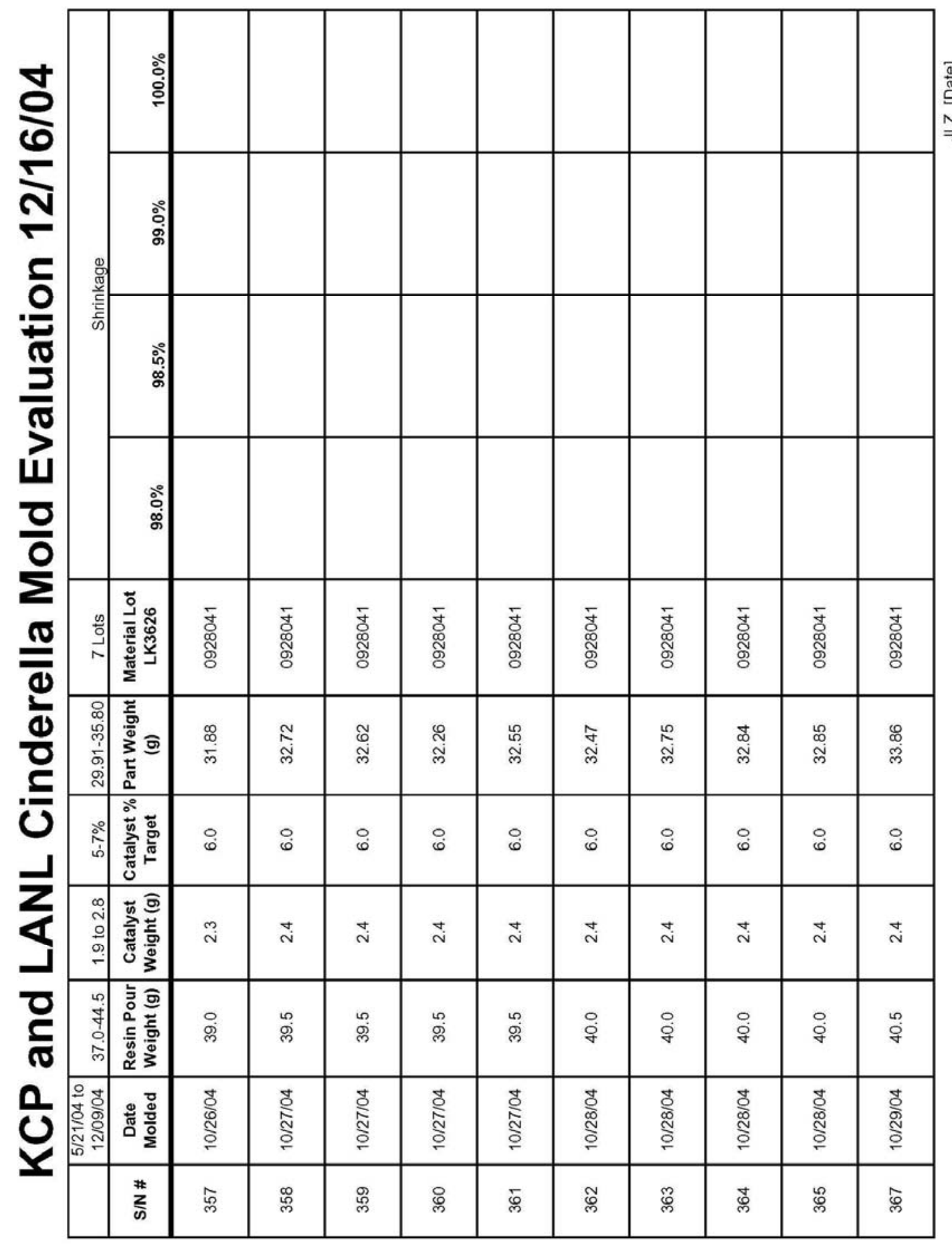




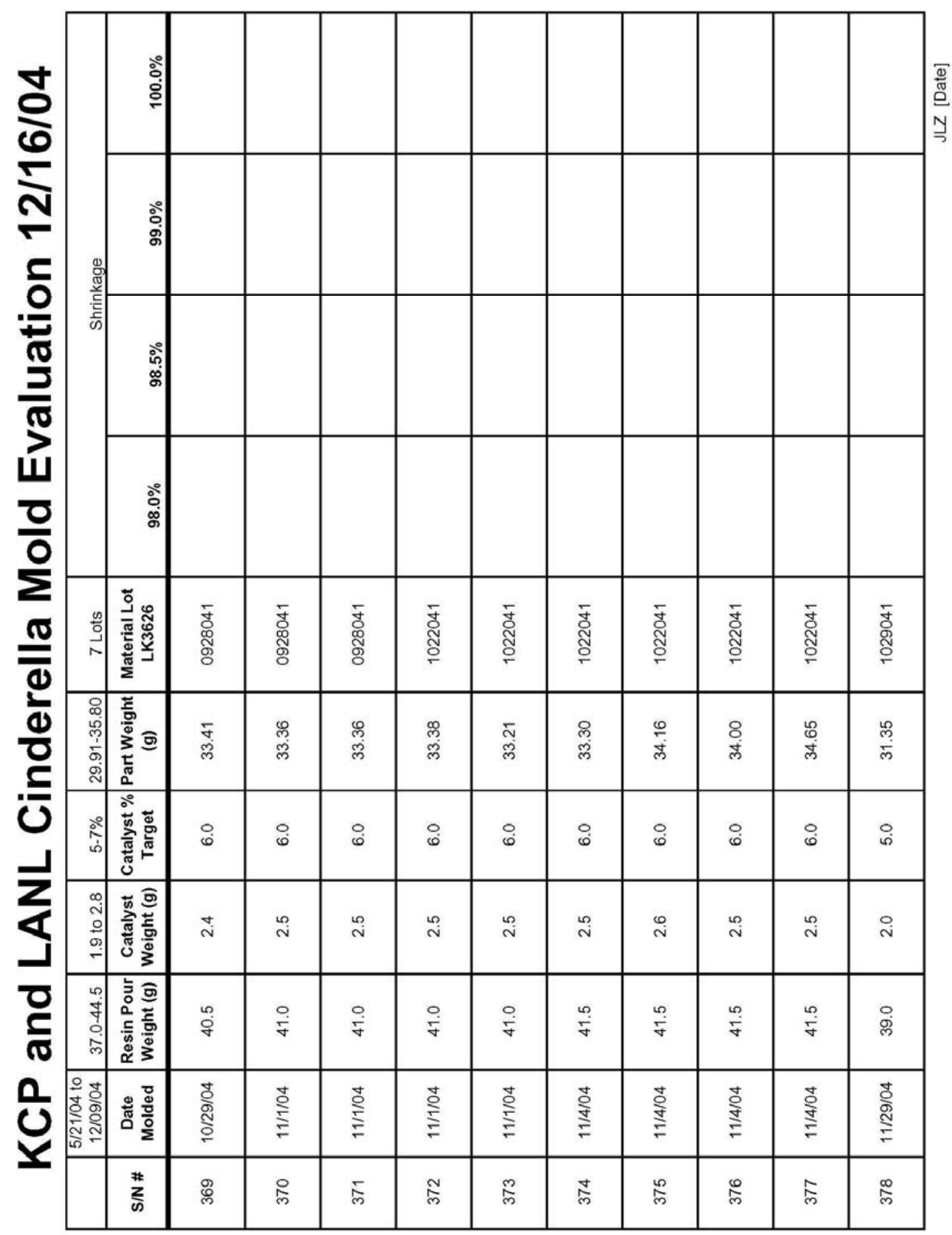




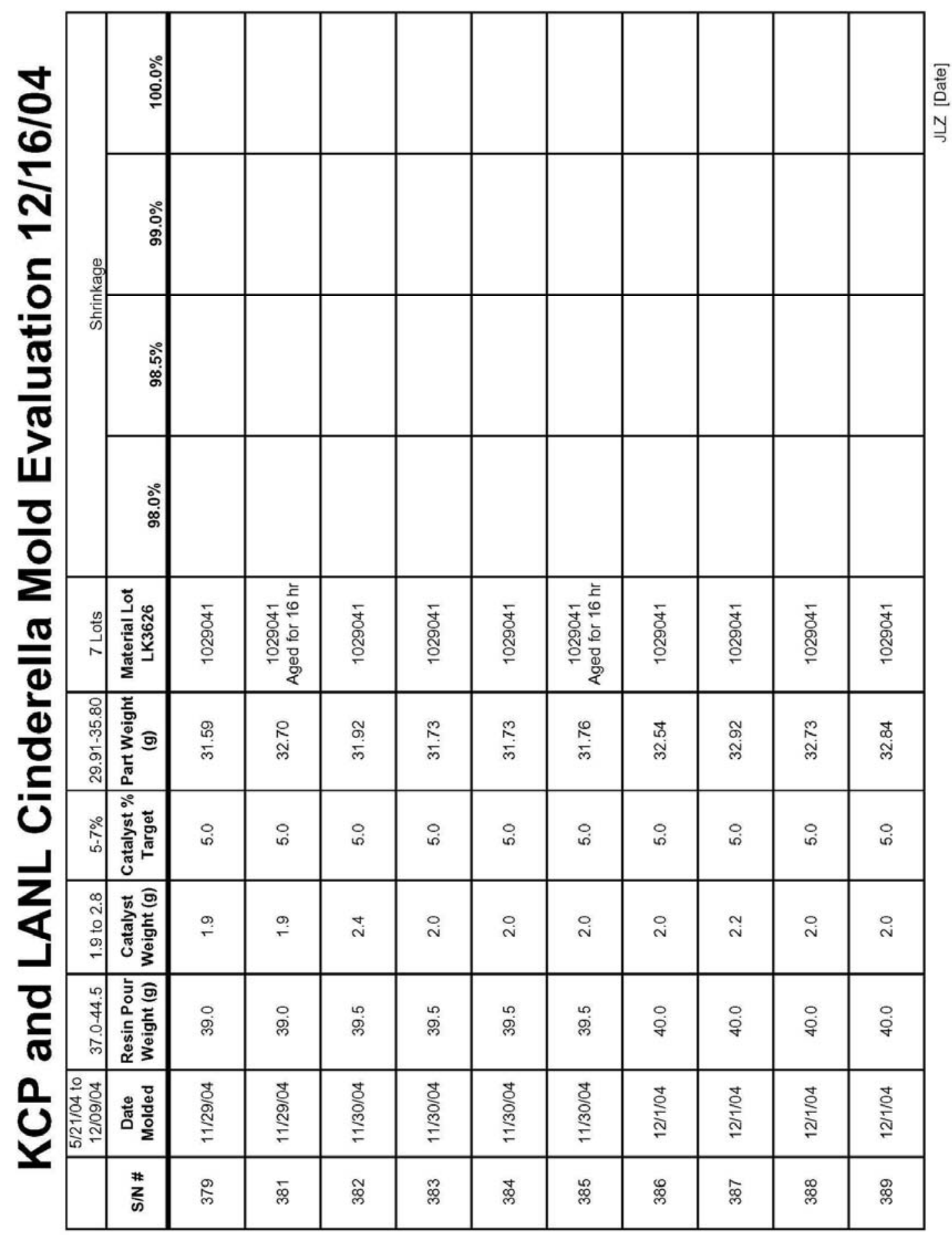




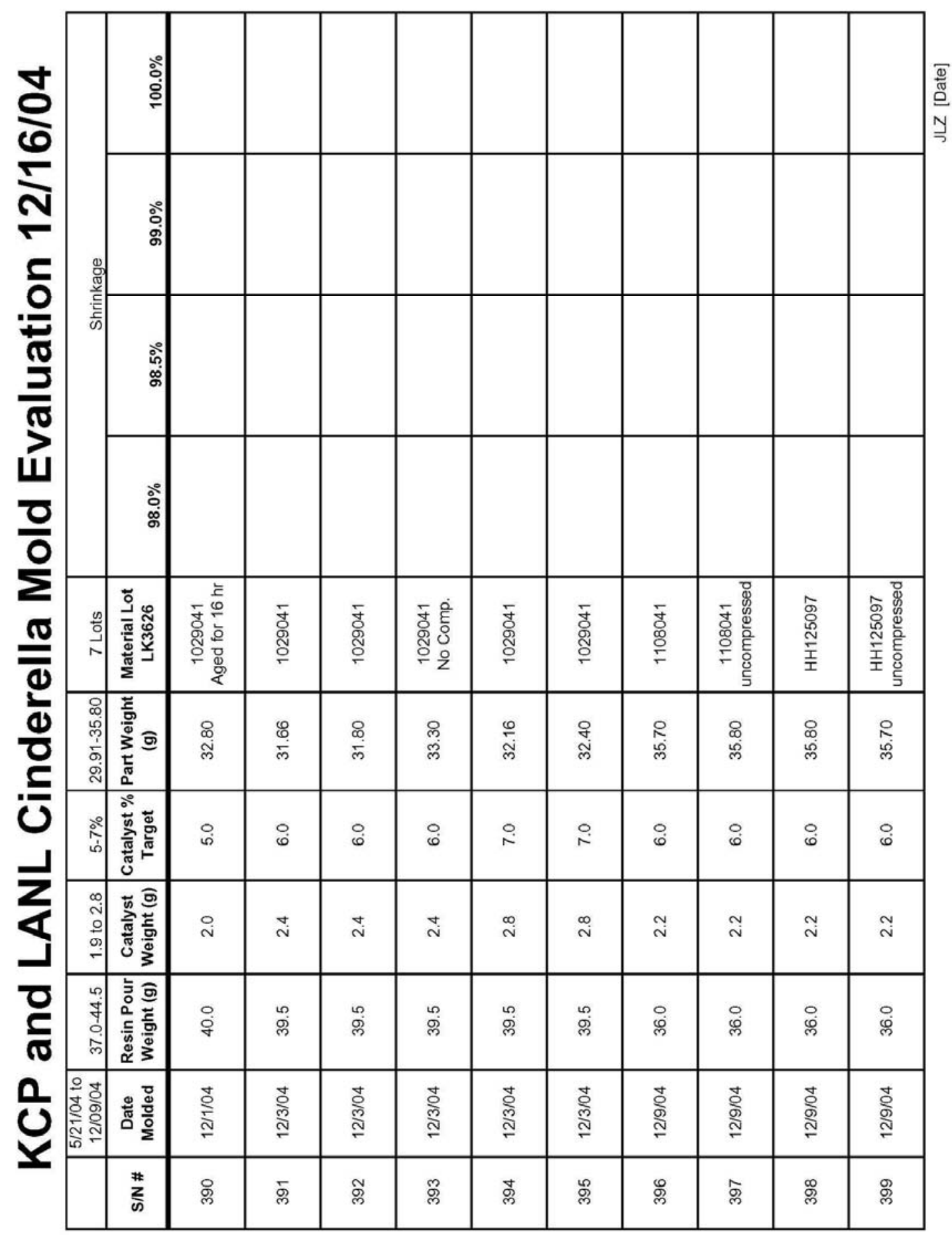




\section{Appendix E}

\section{Statistical Analysis of the Cinderella Mold Evaluation}

An analysis of the "KCP LANL Cinderella Mold Evaluation 12/16/04" dataset was performed to determine the appropriate material shrinkage for proper tooling manufacture. The information was entered into JMP (SAS Corporation, Version 5.1.1) and utilized the Distribution and Capability Analysis features of the software. Each shrinkage factor was analyzed, and the results are shown in Table 1. A concise interpretation of the results is as follows:

- A shrinkage factor of $100 \%$ generates “loose” parts $98.6 \%$ of the time.

- A shrinkage factor of $99 \%$ generates “loose” parts $90.8 \%$ of the time, "tight” parts $1.3 \%$ of the time, and on spec parts $7.9 \%$ of the time.

- A shrinkage factor of $98.5 \%$ generates "loose" parts $26 \%$ of the time, "tight” parts $1.3 \%$ of the time, and on spec parts $72.7 \%$ of the time.

- A shrinkage factor of $98 \%$ generates "loose" parts $1.3 \%$ of the time, "tight" parts $10.4 \%$ of the time, and on spec parts $88.3 \%$ of the time.

This analysis uses a target value of 0 , an upper spec limit of 0.5 , and a lower spec limit of -0.5 .

Table 1: Results of Capability Analysis for Cinderella Test

\begin{tabular}{|l|c|c|c|c|}
\hline & \multicolumn{4}{|c|}{ Shrinkage } \\
\cline { 2 - 5 } & 98 & 98.5 & 99 & 100 \\
\hline $\begin{array}{l}\text { Above Spec } \\
\text { Limit of 0.5 }\end{array}$ & 10.4 & 1.3 & 1.3 & 0 \\
\hline At Spec (0+0.5) & 88.3 & 72.7 & 7.9 & 1.4 \\
\hline $\begin{array}{l}\text { Below Spec } \\
\text { Limit of -0.5 }\end{array}$ & 1.3 & 26 & 90.8 & 98.6 \\
\hline
\end{tabular}




\section{Appendix F \\ KCP Power Point Slides \\ Concluding the Cinderella Mold Evaluation}

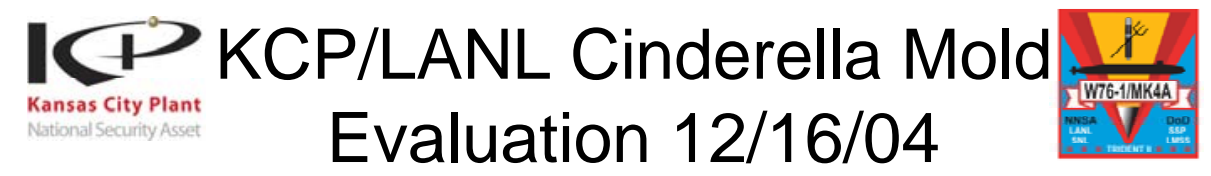

- LANL indicated to KCP that the stress cushions provided to them were not fitting the next assembly.

- The part contour can only be determined by fitting it to a known shrinkage.

- Acrylic was the material of choice for the cavity to allow viewing the stress cushion "fit".

- The next assembly contour was the basis for the acrylic cavities. Four cavities were machined to $2 \%, 1.5 \%, 1 \%$ and $0 \%$ reduction from the design requirement.

The Kansas City Plant is operated and managed by Honeywell Federal Manufacturing \& Technologies, LLC, for the NNSA.

IYA Es:

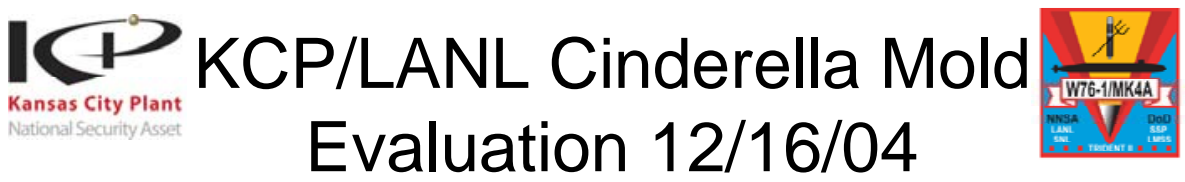

- 77 Stress Cushions Evaluated

- Molded date range 5/21/04 - 12/9/04

- Resin Weight Ranged from $37.0-44.5 \mathrm{~g}$

- Catalyst Ranged from 5-7\%

- 7 Lots LK3626 Evaluated

- Final Part Weight Ranged from 29.9 - $35.8 \mathrm{~g}$

Statistically 3.5\% Shrinkage was Optimum as Determined by LANL. This is based on $2 \%$ from the perform mold and $1.5 \%$ from the Cinderella mold.

The Kansas City Plant is operated and managed by Honeywell Federal Manufacturing \& Technologies, LCC, for the NNSA.

NASE 


\author{
Appendix G \\ GPC Data Set for the $\mathbf{4 0 0 3 0 2 8}$ \\ Polydimethylsiloxanediol - LMWS
}




\section{LMWS GPC Results}

\begin{tabular}{|c|c|c|c|c|c|c|c|c|}
\hline Lot & Location & Date & Mn & Mw & AVG Mn & AVG Mw & & \\
\hline 23808 & 1 & $9 / 13 / 01$ & 1469 & 1787 & & & Red & NuSil \\
\hline 23808 & 1 & $9 / 13 / 01$ & 1469 & 1789 & & & Blue & UCT \\
\hline 23808 & 1 & $9 / 13 / 01$ & 1468 & 1784 & & & & \\
\hline 23808 & 2 & $9 / 13 / 01$ & 1465 & 1777 & & & & \\
\hline 23808 & 2 & $9 / 13 / 01$ & 1467 & 1783 & & & & \\
\hline 23808 & 2 & $9 / 13 / 01$ & 1466 & 1777 & 1467 & 1783 & & \\
\hline 23808 & $\overline{1}$ & $7 / 9 / 03$ & $\overline{1525}$ & $1 \overline{85}$ & & & & \\
\hline 23808 & 1 & $7 / 9 / 03$ & 1526 & 1855 & & & & \\
\hline 23808 & 1 & $7 / 9 / 03$ & 1525 & 1852 & & & & \\
\hline 23808 & 2 & $7 / 9 / 03$ & 1525 & 1852 & & & & \\
\hline 23808 & 2 & $7 / 9 / 03$ & 1520 & 1846 & & & & \\
\hline 23808 & $\underline{2}$ & $7 / 9 / 03$ & 1523 & 1850 & 1524 & 1851 & & \\
\hline 25236 & $\overline{1}$ & $7 / 9 / 03$ & $\overline{1511}$ & 1837 & & & & \\
\hline 25236 & 1 & $7 / 9 / 03$ & 1511 & 1836 & & & & \\
\hline 25236 & 1 & $7 / 9 / 03$ & 1513 & 1844 & & & & \\
\hline 25236 & 2 & $7 / 9 / 03$ & 1515 & 1841 & & & & \\
\hline 25236 & 2 & $7 / 9 / 03$ & 1515 & 1845 & & & & \\
\hline 25236 & 2 & $7 / 9 / 03$ & 1513 & 1842 & 1513. & 1841 & & \\
\hline 29227 & $\overline{1}$ & $7 / 9 / 03$ & $\overline{1531}$ & 1861 & & & & \\
\hline 29227 & 1 & $7 / 9 / 03$ & 1533 & 1848 & & & & \\
\hline 29227 & 1 & $7 / 9 / 03$ & 1531 & 1851 & & & & \\
\hline 29227 & 2 & $7 / 9 / 03$ & 1534 & 1861 & & & & \\
\hline 29227 & 2 & $7 / 9 / 03$ & 1531 & 1853 & & & & \\
\hline 29227 & 2 & $7 / 9 / 03$ & 1534 & 1859 & 1532 & 1856 & & \\
\hline$\overline{33} 189$ & $\overline{1}$ & $\overline{8} / \overline{16} / 04$ & $\overline{1596}$ & $1 \overline{84}$ & & & & \\
\hline 33189 & 1 & $8 / 16 / 04$ & 1597 & 1845 & & & & \\
\hline 33189 & 1 & $8 / 16 / 04$ & 1597 & 1849 & & & & \\
\hline 33189 & 2 & $8 / 16 / 04$ & 1595 & 1842 & & & & \\
\hline 33189 & 2 & $8 / 16 / 04$ & 1594 & 1846 & 1596 & 1845 & & \\
\hline $3 \overline{3} \overline{20}$ & $\overline{1}$ & $8 \overline{8} / \overline{04}$ & $\overline{16} \overline{14}$ & $1 \overline{86} \overline{1}$ & & & & \\
\hline 33420 & 1 & $8 / 8 / 04$ & 1615 & 1873 & & & & \\
\hline 33420 & 1 & $8 / 8 / 04$ & 1601 & 1840 & & & & \\
\hline 33420 & 2 & $8 / 8 / 04$ & 1610 & 1864 & & & & \\
\hline 33420 & 2 & $8 / 8 / 04$ & 1609 & 1859 & & & & \\
\hline 33420 & 2 & $8 / 8 / 04$ & 1602 & 1850 & 1609 & 1858 & & \\
\hline 29227 & $\overline{1}$ & $8 / 18 / 04$ & $15 \overline{36}$ & $182 \overline{0}$ & & & & \\
\hline 29227 & 1 & $8 / 18 / 04$ & 1537 & 1819 & & & & \\
\hline 29227 & 1 & $8 / 18 / 04$ & 1635 & 1902 & & & & \\
\hline 29227 & 2 & $8 / 18 / 04$ & 1537 & 1822 & & & & \\
\hline 29227 & 2 & $8 / 18 / 04$ & 1535 & 1816 & & & & \\
\hline 29227 & $\underline{2}$ & $8 / 18 / 04$ & 1631 & 1893 & 1569. & 1845 & & \\
\hline$\overline{20} \overline{2500} \overline{10}$ & $\overline{1}$ & $-7 / 9 / 03$ & 1648 & $-\overline{8} \overline{7} \overline{3}$ & & & & \\
\hline 20250010 & 1 & $7 / 9 / 03$ & 1652 & 2821 & & & & \\
\hline 20250010 & 1 & $7 / 9 / 03$ & 1673 & 2929 & & & & \\
\hline 20250010 & 2 & $7 / 9 / 03$ & 1653 & 2875 & & & & \\
\hline 20250010 & 2 & $7 / 9 / 03$ & 1647 & 2853 & & & & \\
\hline 20250010 & 2 & $7 / 9 / 03$ & 1648 & 2820 & 1654 & 2862 & & \\
\hline$-1 \overline{95} \overline{390}$ & $\overline{1}$ & $\overline{9} / 13 / 01$ & $16 \overline{6}$ & 2895 & & & & \\
\hline
\end{tabular}




\section{LMWS GPC Results}

\begin{tabular}{|c|c|c|c|c|c|c|}
\hline 195390 & 1 & $9 / 13 / 01$ & 1646 & 2853 & & \\
\hline 195390 & 1 & $9 / 13 / 01$ & 1656 & 2866 & & \\
\hline 195390 & 2 & $9 / 13 / 01$ & 1664 & 2851 & & \\
\hline 195390 & 2 & $9 / 13 / 01$ & 1653 & 2852 & & \\
\hline 195390 & 2 & $9 / 13 / 01$ & 1668 & 2886 & 1659 & 2867 \\
\hline
\end{tabular}

JZ Oct 2004 


\author{
Appendix $\mathrm{H}$ \\ GPC Data Set for the $\mathbf{4 0 0 3 0 2 9}$ \\ Polydimethylsiloxanediol - LHMWS
}




\section{LHMWS GPC Results}

\begin{tabular}{|c|c|c|c|c|c|c|c|c|}
\hline Lot & Location & Date & Mn & Mw & AVG Mn & AVG Mw & & \\
\hline 21502 & 1 & $7 / 9 / 03$ & 11640 & 30689 & & & Red & NuSil \\
\hline 21502 & 1 & $7 / 9 / 03$ & 11301 & 30592 & & & Blue & UCT \\
\hline 21502 & 1 & $7 / 9 / 03$ & 11239 & 30593 & & & & \\
\hline 21502 & 2 & $7 / 9 / 03$ & 11702 & 30771 & & & & \\
\hline 21502 & 2 & $7 / 9 / 03$ & 11775 & 30827 & & & & \\
\hline 21502 & 2 & 7/9/03 & 11757 & 30784 & 11569 & 30709 & & \\
\hline 21502 & 1 & $\overline{9} / 13 / 01$ & $\overline{11} \overline{325}$ & 30830 & & & & \\
\hline 21502 & 1 & $9 / 13 / 01$ & 10263 & 30420 & & & & \\
\hline 21502 & 1 & $9 / 13 / 01$ & 9769 & 30366 & & & & \\
\hline 21502 & 2 & $9 / 13 / 01$ & 11144 & 30663 & & & & \\
\hline 21502 & 2 & $9 / 13 / 01$ & 11348 & 30813 & & & & \\
\hline 21502 & $\underline{2}$ & $9 / 13 / 01$ & 11310 & 30828 & 10860 & 30653 & & \\
\hline 27200 & $\overline{1}$ & $7 / 9 / 03$ & 11610 & 27323 & & & & \\
\hline 27200 & 1 & $7 / 9 / 03$ & 11674 & 27405 & & & & \\
\hline 27200 & 1 & $7 / 9 / 03$ & 11763 & 27491 & & & & \\
\hline 27200 & 2 & $7 / 9 / 03$ & 11499 & 27325 & & & & \\
\hline 27200 & 2 & 7/9/03 & 11904 & 27544 & & & & \\
\hline 27200 & $\underline{2}$ & 7/9/03 & 11536 & 27394 & 11664 & 27414 & & \\
\hline 28998 & $\overline{1}$ & $6 / 18 / 04$ & 11870 & 27583 & & & & \\
\hline 28998 & 1 & $6 / 18 / 04$ & 11678 & 27566 & & & & \\
\hline 28998 & 1 & $6 / 18 / 04$ & 11512 & 27531 & & & & \\
\hline 28998 & 2 & $6 / 18 / 04$ & 11025 & 27332 & & & & \\
\hline 28998 & 2 & $6 / 18 / 04$ & 10997 & 27392 & & & & \\
\hline 28998 & $\underline{2}$ & $6 / 18 / 04$ & 10983 & 27312 & 11344 & 27453 & & \\
\hline 29145 & $\overline{1}$ & $7 / 9 / 03$ & $\overline{11928}$ & 28205 & & & & \\
\hline 29145 & 1 & $7 / 9 / 03$ & 11869 & 28193 & & & & \\
\hline 29145 & 1 & $7 / 9 / 03$ & 11402 & 27982 & & & & \\
\hline 29145 & 2 & $7 / 9 / 03$ & 12243 & 28480 & & & & \\
\hline 29145 & 2 & $7 / 9 / 03$ & 12205 & 28712 & & & & \\
\hline 29145 & $\underline{2}$ & 7/9/03 & 12014 & 28431 & 11944 & 28334 & & \\
\hline 33188 & $\overline{1}$ & $\overline{6} / 18 / 04$ & $\overline{11} \overline{30} \overline{1}$ & 25508 & & & & \\
\hline 33188 & 1 & $6 / 18 / 04$ & 11509 & 25438 & & & & \\
\hline 33188 & 1 & $6 / 18 / 04$ & 11467 & 25445 & & & & \\
\hline 33188 & 2 & $6 / 18 / 04$ & 11981 & 25795 & & & & \\
\hline 33188 & 2 & $6 / 18 / 04$ & 11779 & 25855 & & & & \\
\hline 33188 & 2 & $6 / 18 / 04$ & 11582 & 25636 & 11603 & 25613 & & \\
\hline 33188 & 1 & $8 / 18 / 04$ & 11721 & 28472 & & & & \\
\hline 33188 & 1 & $8 / 18 / 04$ & 11956 & 28578 & & & & \\
\hline 33188 & 1 & $8 / 18 / 04$ & 12330 & 28690 & & & & \\
\hline 33188 & 2 & $8 / 18 / 04$ & 10564 & 27772 & & & & \\
\hline 33188 & 2 & $8 / 18 / 04$ & 11086 & 27852 & & & & \\
\hline 33188 & $\underline{2}$ & $8 / 18 / 04$ & 10580 & 27832 & 11373 & 28199 & & \\
\hline 33419 & $\overline{1}$ & $8 / 16 / 04$ & 12340 & 29341 & & & & \\
\hline 33419 & 1 & $8 / 16 / 04$ & 12439 & 29325 & & & & \\
\hline 33419 & 1 & $8 / 16 / 04$ & 12569 & 29415 & & & & \\
\hline 33419 & 2 & $8 / 16 / 04$ & 12399 & 29237 & & & & \\
\hline 33419 & 2 & $8 / 16 / 04$ & 12204 & 29064 & & & & \\
\hline 33419 & $\underline{2}$ & $8 / 16 / 04$ & 12573 & 29341 & 12421 & 29287 & & \\
\hline
\end{tabular}




\begin{tabular}{|c|c|c|c|c|c|c|}
\hline$\overline{20050} \overline{8}$ & 1 & $\overline{9} / \overline{13} / 01$ & $\overline{10067}$ & $-\overline{32} 175$ & & \\
\hline 2005018 & 1 & $9 / 13 / 01$ & 9920 & 32102 & & \\
\hline 2005018 & 1 & $9 / 13 / 01$ & 9927 & 32132 & & \\
\hline 2005018 & 2 & $9 / 13 / 01$ & 8578 & 31140 & & \\
\hline 2005018 & 2 & $9 / 13 / 01$ & 8628 & 31345 & & \\
\hline 2005018 & 2 & $9 / 13 / 01$ & 8754 & 31267 & 9312 & 31694 \\
\hline$\overline{2} 0 \overline{0} 501 \overline{8}$ & $\overline{1}$ & $\overline{7 / 9} / \overline{03}-$ & $\overline{10289}$ & $-\overline{32} 1 \overline{6} 4$ & & \\
\hline 2005018 & 1 & $7 / 9 / 03$ & 9876 & 31983 & & \\
\hline 2005018 & 1 & $7 / 9 / 03$ & 10306 & 32051 & & \\
\hline 2005018 & 2 & 7/9/03 & 10280 & 32175 & & \\
\hline 2005018 & 2 & $7 / 9 / 03$ & 10177 & 32161 & & \\
\hline 2005018 & 2 & 7/9/03 & 10461 & 32307 & 10232 & 32140 \\
\hline$\overline{20} \overline{25} \overline{00} \overline{30}$ & $\overline{1}$ & $7 \overline{9} / \overline{03}-$ & $\overline{8} 6 \overline{5} \overline{6}$ & $-\overline{31} \overline{3} \overline{3}$ & & \\
\hline 20250030 & 1 & $7 / 9 / 03$ & 9052 & 31674 & & \\
\hline 20250030 & 1 & 7/9/03 & 8848 & 31499 & & \\
\hline 20250030 & 2 & $7 / 9 / 03$ & 8998 & 31733 & & \\
\hline 20250030 & 2 & $7 / 9 / 03$ & 9053 & 31948 & & \\
\hline 20250030 & 2 & 7/9/03 & 9083 & 31653 & 8948 & 31647 \\
\hline
\end{tabular}

JZ Oct 2004 


\author{
Appendix I \\ GPC Data Set for the $\mathbf{4 0 0 3 0 3 0}$ \\ Polydimethylsiloxanediol - HMWS
}




\section{HMWS GPC Results}

\begin{tabular}{|c|c|c|c|c|c|c|}
\hline Lot & Location & Date & Mn & Mw & AVG Mn & AVG $M w$ \\
\hline 23810 & 1 & $9 / 13 / 01$ & 17983 & 50844 & & \\
\hline 23810 & 1 & $9 / 13 / 01$ & 18268 & 50960 & & \\
\hline 23810 & 1 & $9 / 13 / 01$ & 17258 & 50890 & & \\
\hline 23810 & 2 & $9 / 13 / 01$ & 18088 & 50961 & & \\
\hline 23810 & 2 & $9 / 13 / 01$ & 18191 & 51202 & & \\
\hline 23810 & 2 & $9 / 13 / 01$ & 17638 & 50955 & 17904 & 50969 \\
\hline$\overline{2} 38 \overline{10}$ & 1 & $\overline{9 / 1} \overline{3 / 01}$ & $-1 \overline{69}$ & 49531 & & \\
\hline 23810 & 1 & $9 / 13 / 01$ & 17186 & 49526 & & \\
\hline 23810 & 1 & $9 / 13 / 01$ & 17297 & 49629 & & \\
\hline 23810 & 2 & $9 / 13 / 01$ & 15375 & 49375 & & \\
\hline 23810 & 2 & $9 / 13 / 01$ & 16701 & 49154 & & \\
\hline 23810 & 2 & $9 / 13 / 01$ & 17536 & 49634 & 16841 & 49475 \\
\hline 23810 & 1 & $7 / 9 / 03$ & $16 \overline{96}$ & $\overline{49018}$ & & \\
\hline 23810 & 1 & $7 / 9 / 03$ & 17905 & 49335 & & \\
\hline 23810 & 1 & 7/9/03 & 16995 & 49322 & & \\
\hline 23810 & 2 & $7 / 9 / 03$ & 16486 & 48982 & & \\
\hline 23810 & 2 & $7 / 9 / 03$ & 16696 & 49066 & & \\
\hline 23810 & 2 & $7 / 9 / 03$ & 16414 & 48970 & 16865 & 49116 \\
\hline $257 \overline{16}$ & 1 & $7 / 9 / 03$ & 27061 & 55061 & & \\
\hline 25716 & 1 & $7 / 9 / 03$ & 20522 & 55050 & & \\
\hline 25716 & 1 & $7 / 9 / 03$ & 20040 & 54891 & & \\
\hline 25716 & 2 & $7 / 9 / 03$ & 21352 & 55185 & & \\
\hline 25716 & 2 & $7 / 9 / 03$ & 21590 & 55241 & & \\
\hline 25716 & 2 & $7 / 9 / 03$ & 20612 & 55062 & 20863 & 55082 \\
\hline$\overline{29328}$ & 1 & $\overline{7 / 9 / 0} \overline{3}$ & $1 \overline{5026}$ & $5 \overline{54} \overline{43}$ & & \\
\hline 29328 & 1 & $7 / 9 / 03$ & 15407 & 55632 & & \\
\hline 29328 & 1 & $7 / 9 / 03$ & 15178 & 55838 & & \\
\hline 29328 & 2 & $7 / 9 / 03$ & 15545 & 55824 & & \\
\hline 29328 & 2 & $7 / 9 / 03$ & 15543 & 55738 & & \\
\hline 29328 & 2 & 7/9/03 & 15492 & 55793 & 15365 & 49948 \\
\hline$\overline{3} \overline{3190}$ & 1 & $-\overline{6 / 1} \overline{8 / 04}$ & $-185 \overline{86}$ & $5 \overline{4521}$ & & \\
\hline 33190 & 1 & $6 / 18 / 04$ & 18547 & 54496 & & \\
\hline 33190 & 1 & $6 / 18 / 04$ & 19386 & 54622 & & \\
\hline 33190 & 2 & $6 / 18 / 04$ & 18191 & 54432 & & \\
\hline 33190 & 2 & $6 / 18 / 04$ & 18086 & 54270 & & \\
\hline 33190 & 2 & $6 / 18 / 04$ & 18821 & 54511 & 18603 & 54475 \\
\hline$\overline{3} \overline{3421}$ & 1 & $\overline{8} / 8 / 04$ & $17 \overline{69}$ & $5 \overline{27} \overline{53}$ & & \\
\hline 33421 & 1 & $8 / 8 / 04$ & 17250 & 52449 & & \\
\hline 33421 & 1 & $8 / 8 / 04$ & 17709 & 52656 & & \\
\hline 33421 & 2 & $8 / 8 / 04$ & 19139 & 54094 & & \\
\hline 33421 & 2 & $8 / 8 / 04$ & 18141 & 53990 & & \\
\hline 33421 & 2 & $8 / 8 / 04$ & 17414 & 53916 & 17887 & 53310 \\
\hline$\overline{3} \overline{3190}$ & 1 & $\overline{8 / 1} \overline{8} / \overline{04}$ & $-1 \overline{31} \overline{50}$ & $5 \overline{51} \overline{47}$ & & \\
\hline 33190 & 1 & $8 / 18 / 04$ & 13890 & 55206 & & \\
\hline 33190 & 2 & $8 / 18 / 04$ & 13479 & 55612 & & \\
\hline 33190 & 2 & $8 / 18 / 04$ & 13570 & 55639 & & \\
\hline 33190 & 2 & $8 / 18 / 04$ & 13718 & 55369 & 13561 & 55395 \\
\hline
\end{tabular}

Red NuSil

Blue UCT 


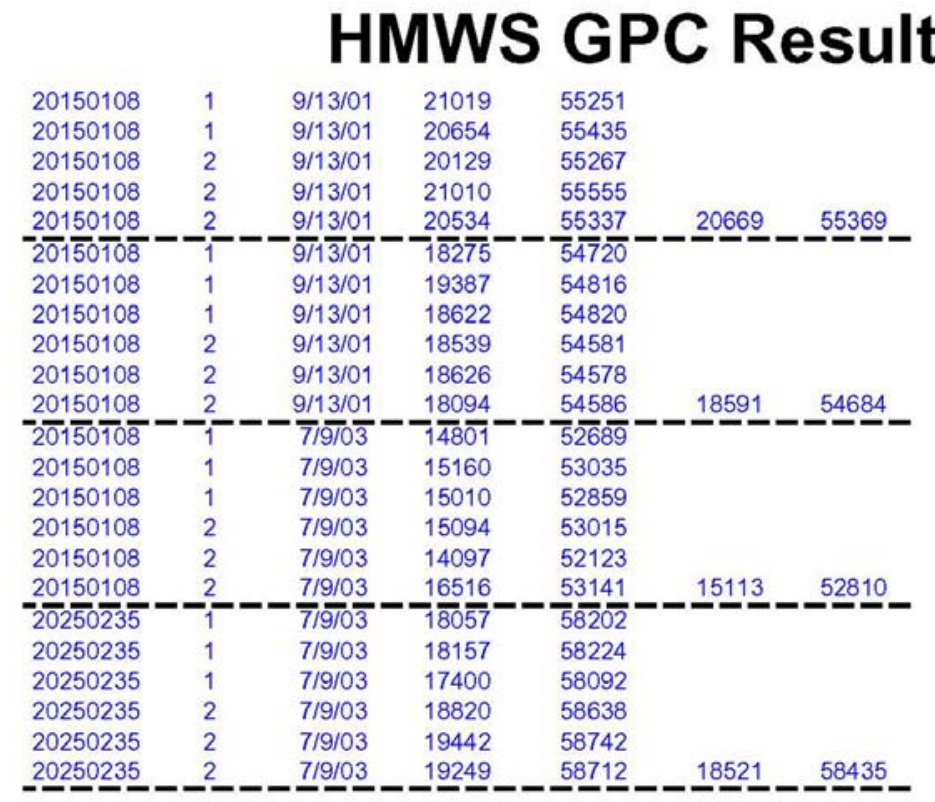




\author{
Appendix $\mathbf{J}$ \\ GPC Data Set for the $\mathbf{4 0 0 3 0 3 1}$ \\ Polymethylhydrogensiloxane - PMHS
}




\section{PMHS GPC Results}

\begin{tabular}{|c|c|c|c|c|c|c|c|c|}
\hline Lot & Location & Date & Mn & Mw & AVG Mn & AVG Mw & & \\
\hline 33417 & 1 & $8 / 13 / 04$ & 3831 & 7519 & & & Red & NuSil \\
\hline 33417 & 1 & $8 / 13 / 04$ & 3857 & 7519 & & & Blue & UCT \\
\hline 33417 & 1 & $8 / 13 / 04$ & 3922 & 7530 & & & Black & Dow Corning \\
\hline 33417 & 2 & $8 / 13 / 04$ & 3982 & 7660 & & & & \\
\hline 33417 & 2 & $8 / 13 / 04$ & 3870 & 7577 & & & & \\
\hline 33417 & $\underline{2}$ & $8 / 13 / 04$ & 3867 & 7608 & 3888 & 7569 & & \\
\hline$\overline{33} 181$ & $\frac{7}{1}$ & $\overline{6} / \overline{18} / 04$ & $\overline{4069}$ & $7 \overline{59} 2$ & & & & \\
\hline 33181 & 1 & $6 / 18 / 04$ & 4080 & 7683 & & & & \\
\hline 33181 & 1 & $6 / 18 / 04$ & 4049 & 7617 & & & & \\
\hline 33181 & 2 & $6 / 18 / 04$ & 4890 & 7630 & & & & \\
\hline 33181 & 2 & $6 / 18 / 04$ & 4971 & 7620 & & & & \\
\hline 33181 & 2 & $6 / 18 / 04$ & 4964 & 7539 & 4504 & 7614 & & \\
\hline 29079 & $\frac{1}{1}$ & $7 \sqrt{7 / 9}=$ & $\overline{4231}$ & 8221 & & & & \\
\hline 29079 & 1 & 7/9/03 & 4188 & 8234 & & & & \\
\hline 29079 & 1 & 7/9/03 & 4200 & 8238 & & & & \\
\hline 29079 & 2 & $7 / 9 / 03$ & 4045 & 8151 & & & & \\
\hline 29079 & 2 & 7/9/03 & 4044 & 8175 & & & & \\
\hline 29079 & 2 & $7 / 9 / 03$ & 4015 & 8159 & 4121. & 8196 & & \\
\hline 24209 & $\overline{1}$ & $7 / 9 / 03$ & 3888 & -7779 & & & & \\
\hline 24209 & 1 & $7 / 9 / 03$ & 3836 & 7747 & & & & \\
\hline 24209 & 1 & $7 / 9 / 03$ & 3836 & 7838 & & & & \\
\hline 24209 & 2 & $7 / 9 / 03$ & 3833 & 7727 & & & & \\
\hline 24209 & 2 & $7 / 9 / 03$ & 3843 & 7813 & & & & \\
\hline 24209 & 2 & 7/9/03 & 3895 & 7782 & 3855 & 7781 & & \\
\hline-23784 & $\frac{\pi}{1}$ & $-7 / 9 / 03-$ & $\overline{3583}$ & $8 \overline{579}$ & & & & \\
\hline 23784 & 1 & $7 / 9 / 03$ & 3548 & 8566 & & & & \\
\hline 23784 & 1 & 7/9/03 & 3652 & 8603 & & & & \\
\hline 23784 & 2 & $7 / 9 / 03$ & 3737 & 8739 & & & & \\
\hline 23784 & 2 & $7 / 9 / 03$ & 3697 & 8751 & & & & \\
\hline 23784 & 2 & $7 / 9 / 03$ & 3725 & 8647 & 3657 & 8648 & & \\
\hline 23784 & $\frac{2}{1}$ & $\overline{9} / 13 / 01$ & $\overline{3683}$ & $-915 \overline{3}$ & & & & \\
\hline 23784 & 1 & $9 / 13 / 01$ & 3602 & 9351 & & & & \\
\hline 23784 & 1 & 9/13/01 & 3623 & 9586 & & & & \\
\hline 23784 & 2 & $9 / 13 / 01$ & 3609 & 9371 & & & & \\
\hline 23784 & 2 & 9/13/01 & 3600 & 9366 & & & & \\
\hline 23784 & 2 & $9 / 13 / 01$ & 3607 & 9410 & 3621 & 9373 & & \\
\hline$\overline{33181}$ & 1 & $\overline{8} / 18 / 04$ & $\overline{3} 688$ & $7 \overline{404}$ & & & & \\
\hline 33181 & 1 & $8 / 18 / 04$ & 3752 & 7416 & & & & \\
\hline 33181 & 1 & $8 / 18 / 04$ & 3771 & 7493 & & & & \\
\hline 33181 & 2 & $8 / 18 / 04$ & 3733 & 7443 & & & & \\
\hline 33181 & 2 & $8 / 18 / 04$ & 3708 & 7364 & & & & \\
\hline 33181 & 2 & $8 / 18 / 04$ & 3713 & 7453 & 3728 & 7429 & & \\
\hline$\overline{24} 209$ & $\frac{7}{9}$ & $\overline{9} / 13 / 01$ & $\overline{3759}$ & $9 \overline{3} 2 \overline{5}$ & & & & \\
\hline 24209 & 1 & 9/13/01 & 3725 & 9348 & & & & \\
\hline 24209 & 1 & $9 / 13 / 01$ & 3770 & 9421 & & & & \\
\hline 24209 & 2 & $9 / 13 / 01$ & 3644 & 9200 & & & & \\
\hline 24209 & 2 & $9 / 13 / 01$ & 3660 & 9289 & & & & \\
\hline 24209 & $\underline{2}$. & $9 / 13 / 01$ & 3620 & 9305 & 3696 & $9315=$ & & \\
\hline
\end{tabular}




\section{PMHS GPC Results}

\begin{tabular}{|c|c|c|c|c|c|c|}
\hline$\overline{2005260}$ & & $\overline{9} / 13 / 01$ & $\overline{4} 9 \overline{8} 6$ & $\overline{162} \overline{20}$ & & \\
\hline 2005260 & 1 & $9 / 13 / 01$ & 4989 & 16018 & & \\
\hline 2005260 & 1 & $9 / 13 / 01$ & 5001 & 16396 & & \\
\hline 2005260 & 2 & $9 / 13 / 01$ & 5128 & 16631 & & \\
\hline 2005260 & 2 & $9 / 13 / 01$ & 5199 & 16240 & & \\
\hline 2005260 & 2 & $9 / 13 / 01$ & 5118 & 16159 & 5070 & 16277 \\
\hline$\overline{2} 0 \overline{5} \overline{2} 6 \overline{0}$ & $\overline{1}$ & $7 \sqrt{9} / \overline{03}$ & $\overline{5} 1 \overline{3} 0$ & $\overline{1} \overline{6} 6 \overline{62}$ & & \\
\hline 2005260 & 1 & $7 / 9 / 03$ & 4932 & 16201 & & \\
\hline 2005260 & 1 & 7/9/03 & 5290 & 15740 & & \\
\hline 2005260 & 2 & 7/9/03 & 4668 & 15410 & & \\
\hline 2005260 & 2 & 7/9/03 & 4761 & 15346 & & \\
\hline 2005260 & 2 & 7/9/03 & 5086 & 15470 & 4978 & 15638 \\
\hline$-\overline{78} \overline{347} \overline{1}$ & $\overline{1}$ & $\overline{10 / 6 / 0} 4$ & $\overline{4} 5 \overline{19}$ & $\overline{10} \overline{3} \overline{17}$ & & \\
\hline 783471 & 1 & $10 / 6 / 04$ & 4526 & 10393 & & \\
\hline 783471 & 1 & $10 / 6 / 04$ & 4412 & 10352 & & \\
\hline 783471 & 2 & $10 / 6 / 04$ & 4422 & 10464 & & \\
\hline 783471 & 2 & $10 / 6 / 04$ & 4603 & 10275 & & \\
\hline 그는. & $\underline{2}$ & 10/6/04 & 4507. & 10264 & -4498. & 10344 \\
\hline $9 \overline{53} 815$ & & 10167 & 3512 & $-7 \overline{322}$ & & \\
\hline 953815 & 1 & $10 / 6 / 04$ & 3550 & 7321 & & \\
\hline 953815 & 1 & $10 / 6 / 04$ & 3523 & 7291 & & \\
\hline 953815 & 2 & $10 / 6 / 04$ & 3278 & 7064 & & \\
\hline 953815 & 2 & $10 / 6 / 04$ & 3293 & 7100 & & \\
\hline 953815 & 2 & $10 / 6 / 04$ & 3294 & 7113 & 3408 & 7202 \\
\hline
\end{tabular}

JZ Oct 2004 